\title{
LA LARGA HUELLA EN EL TERRITORIO DE LAS VIVIENDAS SECUNDARIAS ILEGALES. EL EJEMPLO DE GILET (VALENCIA)
}

\section{RESUMEN}

Los grupos de viviendas secundarias ilegales desarrolladas en España en el entorno de las principales áreas urbanas entre 1960 y 1985 han dejado una profunda huella negativa en el territorio que perdura casi medio siglo después y que en algunos aspectos resulta de muy difícil solución. Las principales consecuencias son desorden territorial, importantes impactos ambientales y paisajísticos, carencia o mala calidad de infraestructuras urbanas, servicios y equipamientos públicos, que acaban siendo una carga económica para la comunidad e incluso generando conflictos políticos que han complicado la gobernanza local. A partir del estudio del municipio de Gilet (Valencia), un ejemplo paradigmático de este proceso, se han analizado los impactos actuales en el territorio y los factores que los determinan. Los resultados obtenidos pueden generalizarse para otras zonas de España donde se desarrollaron estos grupos de viviendas. La ilegalidad sustancial de este peculiar mercado urbanístico español es la causa principal de esos problemas territoriales, de su perdurabilidad en el tiempo y de la dificultad para solucionarlos.

Palabras clave: España; Gilet (Valencia); impactos territoriales; viviendas secundarias ilegales.

\section{Abstract}

The clusters of second homes built illegally in Spain near the main urban areas between 1960 and 1985 have left a profound negative footprint in the territory. Most of these impacts remain half a cen-

a Departamento de Geografía. Universitat de València

Blasco Ibáñez 28, Facultad de Geografía e Historia, 46010-Valencia

elbo@uv.es

Fecha de recepción: mayo 2019. Fecha de aceptación: julio 2019. 
tury later and some are very difficult to solve. The main consequences are territorial disorder, important environmental and landscape impacts, as well as lack or poor quality of urban infrastructure and public services. These issues end up creating an economic burden on the community and they even lead to political conflicts that complicate local governance. Based on a case study of the municipality of Gilet (Valencia), which offers a paradigmatic example of this process, the current territorial impacts and the explaining factors have been analyzed. The results obtained can be generalized to other areas of Spain where second homes built illegally were developed. The substantial illegality of this peculiar urban market in Spain is the main cause of these territorial problems, their endurance in time and the difficulty to solve them.

KeYwords: Gilet (Valencia); illegal second homes; Spain; territorial impacts.

\section{INTRODUCCIÓN}

En el entorno de las principales áreas urbanas españolas surgieron numerosos núcleos de viviendas secundarias ilegales en la etapa del desarrollismo (Diputación de Valencia, 1983; García Bellido, 1986) y años más tarde también en otras regiones (Defensor del Pueblo Andaluz, 2000; Jiménez Barrado, 2018). Es un producto urbanístico singular creado para atender la demanda insatisfecha de segunda residencia de una clase popular urbana cuya escasa capacidad económica no le permitía acceder a las urbanizaciones legales.

La ilegalidad es la que lo hace posible, porque permite prescindir de la inversión exigida por ley (obras de urbanización, cesiones de suelo...) limitando el gasto a la compra de la parcela y a la construcción de la casa poco a poco y sin proyecto técnico; y porque posibilita la ubicación en terrenos mucho más baratos que el planeamiento había excluido de la función residencial por su valor ambiental, aislamiento, mala accesibilidad, dispersión, fuerte pendiente $\mathrm{u}$ otras condiciones inadecuadas.

En este trabajo se pretende conocer y explicar, casi medio siglo después de su inicio, las consecuencias territoriales de estas "urbanizaciones" irregulares que constituyen "una de las hipotecas más gravosas del franquismo para la gestión del territorio" (Nel·lo, 2011a, 95). No hay estudios detallados sobre ellas desde esta perspectiva. A partir de mediados de los años 90, la mayor parte de la literatura académica se ha centrado en la prevención, regularización y control de estas parcelaciones y viviendas ilegales con un enfoque casi exclusivamente jurídico (Betrán, \& Franco, 1994; Gobierno de Aragón, 1997; Martín Fernández, 2011; Olmedo 2016); aunque en ella se encuentran referencias interesantes para el objetivo aquí buscado. Los estudios que tratan aspectos territoriales - la mayoría de regiones como Andalucía (Fajardo, 2003) en que estas viviendas se dieron en una etapa más tardía- son casi todos de ámbito muy local, salvo una reciente Tesis Doctoral sobre Extremadura (Jiménez Barrado, 2018). Una excelente descripción de su problemática global se encuentra en un artículo sobre la Ley 3/2009 de la Generalitat de Cataluña para la regularización de estas urbanizaciones; pero es muy sucinta por corresponder a la introducción del tema analizado (Nel·lo, 2011a). 
La primera hipótesis a comprobar es que los desarrollos urbanísticos ilegales dejan siempre una profunda huella negativa en el territorio; y que ésta, además, perdura mucho tiempo porque la eliminación o mitigación de los problemas ocasionados es complicada y en ocasiones casi imposible y exige elevados costes privados y públicos.

La segunda hipótesis es que esa huella territorial y su larga permanencia obedece fundamentalmente a la ilegalidad original -sustancial para la existencia de este producto urbanístico- porque supone una contradicción intrínseca con su normalización posterior; resulta muy difícil reconducir a la legalidad lo que sólo tenía sentido fuera de ella.

La investigación se plantea a partir del estudio detallado del municipio de Gilet (Valencia) que constituye un ejemplo paradigmático de este proceso; entre 1960 y 1985 se construyeron en él 256 viviendas secundarias al margen de la legalidad urbanística casi todas agrupadas en 9 núcleos emplazados de manera desordenada por todo el término, al mismo tiempo que se promovían las urbanizaciones legales de La Paz y Santo Espíritu (Burriel, 2018).

Situado en la periferia norte del área metropolitana de Valencia, a $28 \mathrm{~km}$ de la capital y a $6 \mathrm{~km}$ de Sagunt que tuvo una importante industria siderúrgica hasta 1983, presenta las características territoriales de las zonas de España donde se desarrollaron en esos años residencias secundarias: espacios rurales de montaña media con atractivo natural y paisajístico, cercanos a áreas urbanas dinámicas (Nel·lo, 2011a, 85- 87; Hermosilla, 1992, 99-102). Pero a la vez tiene rasgos que favorecen la aparición del mercado de viviendas ilegales: suelos de muy bajo precio por su escaso valor productivo o por su inadecuación para el uso residencial por las fuertes pendientes -superiores al 10\% en las 4/5 partes de Gilet- (García Bellido, 1986; Betrán y Franco, 1994, 49), así como una situación algo marginal respecto al centro metropolitano (Comunidad de Madrid, 1984, 46-48). Terrenos de poco coste y casi total ausencia de inversión en infraestructuras urbanísticas facilitaron la oferta por promotores ocasionales no profesionales y pequeños propietarios locales de parcelas ilegales muy baratas. Los compradores pertenecían a una clase popular urbana de bajo poder adquisitivo, en su inmensa mayoría vecinos de los barrios de la periferia de Valencia -trabajadores industriales, de la construcción o empleados del sector servicios con poca cualificación- o del cercano Port de Sagunt en este caso con predominio de los obreros de Altos Hornos.

Los resultados obtenidos del análisis detallado del caso de Gilet pueden considerarse válidos para las otras zonas de España que conocieron desarrollos residenciales de este tipo, como se va a corroborar con referencias genéricas en obras de carácter general sobre las parcelaciones ilegales, con otras más puntuales y parciales en las de ámbito local y con numerosas noticias en los medios de comunicación.

\section{Dificultades PARA UNA PLANIFICACIÓN URBANÍSTICA RACIONAL}

La primera consecuencia de la proliferación de los núcleos de viviendas ilegales es un territorio carente de ordenación que el planeamiento posterior no consigue reconducir. Esta 
falta de racionalidad en la localización de las zonas residenciales es la causa principal de la mayoría de los otros problemas detectados.

\section{El PGOU de Gilet de 1994}

El gobierno local de Gilet surgido de las elecciones de 1983, preocupado por la grave problemática que suponía la proliferación de núcleos de edificaciones irregulares por todo su territorio (Figura 1) decidió primero realizar un "censo" de estas casas y controlar que no se siguieran construyendo; y luego, en 1985, acordó elaborar un nuevo PGOU que ordenara adecuadamente el municipio.

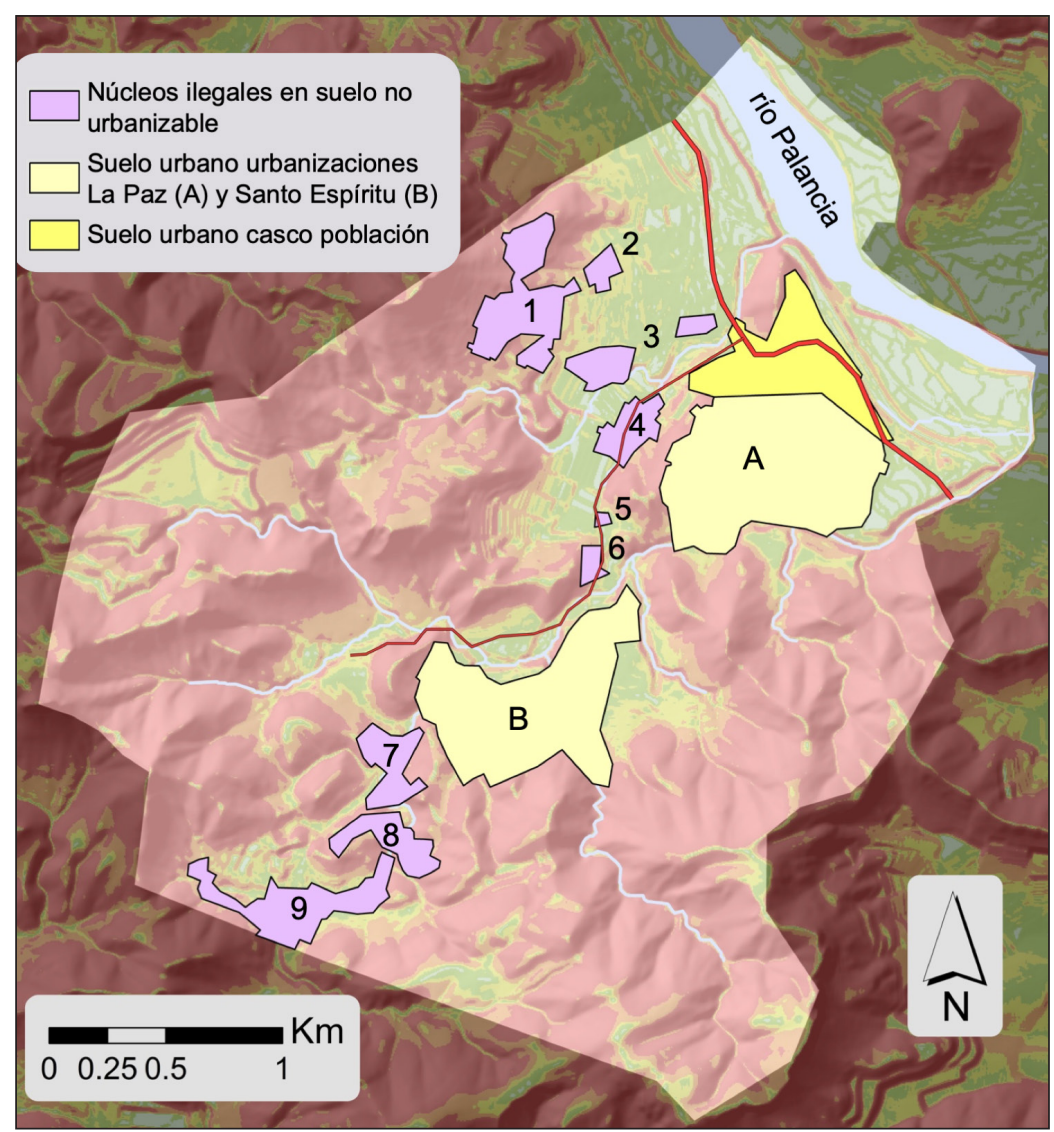

Figura 1. Los núcleos de viviendas secundarias ilegales de Gilet en 1983: 1. Balcó de la Penya; 2. Camí de la Costera; 3. Pla de la Venta; 4. Camí del Convent-1; 5. Camí del Convent-2; 6. Camí del Convent-3; 7. Vidriera; 8. Clot d’Oliver; 9. Calderona. Elaboración: E. Burriel y A. Calvo. 
La larga gestación del PGOU -9 años hasta su aprobación por la administración autonómica en 1994- ya muestra la dificultad de dar una respuesta satisfactoria a la situación creada. La Memoria del Plan contiene un análisis lúcido del territorio de Gilet, sus valores ambientales y las consecuencias de las construcciones irregulares y plantea unos objetivos claros y correctos en sus propuestas de desarrollo urbanístico. Pero el enorme conflicto jurídico, económico y sociopolítico que suponía la existencia de 9 núcleos ilegales dispersos por todo el término condicionó las decisiones del PGOU y llevó al ayuntamiento a adoptar una solución excepcional que sin embargo no consiguió resolver el problema.

No se optó por el restablecimiento de la legalidad mediante la eliminación de lo construido en suelo no urbanizable porque el elevado número de viviendas desbordaba la capacidad de gestión municipal y los recursos judiciales iban a paralizar los derribos durante años haciendo ineficaz la drástica medida; más aún cuando el ayuntamiento se encontró con la sorpresa de que bastantes propietarios aportaban una licencia, concedida en su día por el ayuntamiento pese a la falta de base legal para ello (Burriel, 2018, 29-30). Pero también porque en aquellos años en Gilet, como en muchos municipios rurales, era mayoritaria la creencia de que estas urbanizaciones, legales o no, representaban una oportunidad para incorporarse "al tren del crecimiento y desarrollo" (Consejero de Ordenación del Territorio de Aragón, en Betrán, \& Franco, 1994, 9; ver también Olmedo, 2016, 2 y Jiménez Barrado, Delgado, \& Campesino, 2017, 89).

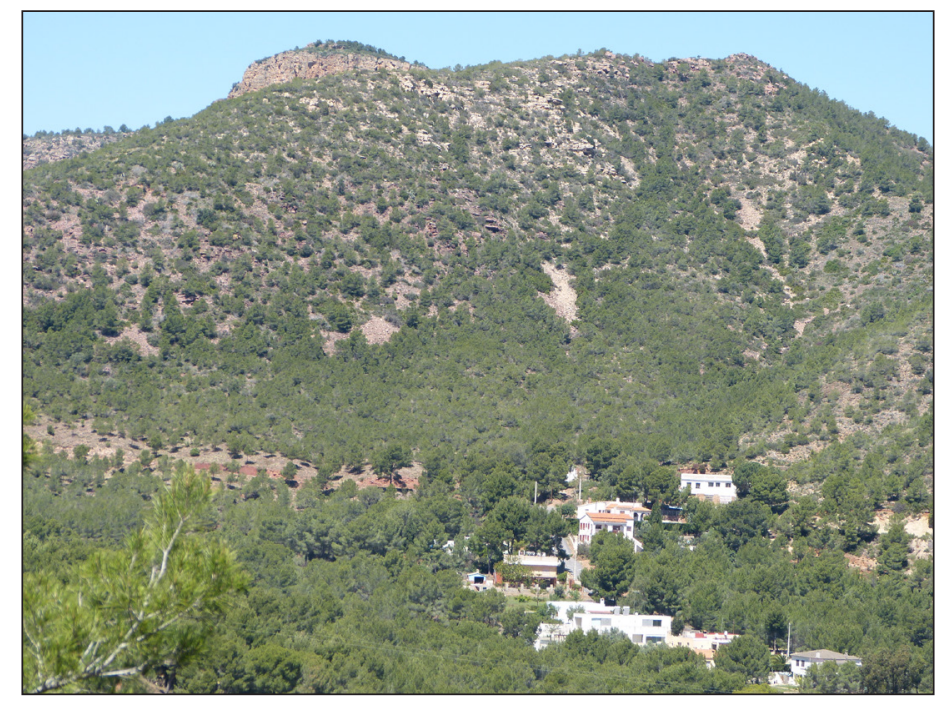

Figura 2. Viviendas situadas hoy dentro del Parque Natural de la Sierra Calderona clasificadas como suelo urbano por el PGOU de 1994 (camí del Pic de l'Águila, núcleo de Calderona). Fotografía E. Burriel, abril de 2019. 
$\mathrm{Ni}$ siquiera se contempló dejarlas en suelo no urbanizable "fuera de ordenación"; si no todas, al menos las que formaban grupos muy pequeños (Camí del Convent-2 y Camí del Convent-3), las de acceso muy difícil (zona alta del núcleo de Clot d'Oliver) o las situadas en espacios de más valor ambiental (camí del Pic del Águila en el de Calderona. Figura 2).

También se rechazó clasificar ese suelo como urbanizable, la opción más acorde con la lógica urbanística y que para su consolidación legal exigía a los propietarios ejecutar la urbanización y ceder suelo para viario, zonas verdes y dotaciones públicas. No se consideró factible porque su gestión resultaba muy complicada y casi imposible: con el terreno ya parcelado sin haberse hecho las cesiones de suelo obligatorias y con muchas parcelas construidas hasta su límite con la calle es muy difícil una reparcelación que pueda cumplir las exigencias legales. Esta imposibilidad de gestionar las parcelaciones ilegales como suelo urbanizable ya se señalaba en los primeros análisis del problema (Diputación de Valencia, 1983, 106-107). Sin embargo, la existencia entonces de muchas parcelas vacías en todos los núcleos -sobre todo en Balcó de la Penya y Calderona- hubiera permitido la obtención de suelo para zonas verdes y dotaciones y en algunas zonas para calles de adecuada anchura y trazado.

En esa tesitura el ayuntamiento, cuya principal preocupación era evitar el conflicto social, optó porque el PGOU clasificara directamente como urbano todo el suelo parcelado ilegalmente ${ }^{1}$ acogiéndose al artículo 63.a de la Ley del Suelo de 1975 que lo permitía "en áreas consolidadas por la edificación en al menos dos terceras partes de su superficie”.

Para aceptar esta opción excepcional la Consellería d'Obres Públiques i Urbanisme de la Generalitat Valenciana exigió el compromiso de los propietarios de ejecutar a posteriori las infraestructuras básicas -acceso rodado en condiciones, urbanización completa del viario, agua potable, electricidad y alcantarillado- obviando las cesiones de suelo para dotaciones. Los diversos núcleos se comprometieron a ello en reuniones públicas con el alcalde que no les exigió aval bancario ni una ratificación por escrito; una ingenuidad política, aunque entendible en un municipio pequeño en el que las relaciones se basan en la confianza y el conocimiento personal. Para ayudar a los parcelistas, en su mayoría de bajo nivel de renta, la Consellería se ocuparía de construir el colector general de aguas residuales hasta cada núcleo y el ayuntamiento de buscar subvenciones para mejorar los accesos².

Sin embargo, esta opción tan favorable a los propietarios no sirvió para solucionar el problema porque una vez aprobado el PGOU los propietarios de Balcó de la Penya, Calderona, Camí del Convent-1 y Camí de la Costera, que suponían el 72\% de las parcelas, se negaron a cumplir lo acordado. Y ello a pesar de que el ayuntamiento les había conseguido préstamos bancarios en condiciones muy favorables con la única garantía de su vivienda y de que la

1 Sólo quedaron en suelo no urbanizable 29 viviendas aisladas (Burriel, 2018, 31).

2 La Consellería ejecutó en 1992 el colector, que por la dispersión de los núcleos necesitó 9 km. de tubería y costó 42 millones de ptas. El ayuntamiento consiguió ayudas del Plan de Caminos Rurales del Ministerio de Agricultura para el asfaltado del acceso al Balcó de la Penya y de la vía pecuaria hasta el grupo de Calderona. 
reclasificación de sus terrenos como urbanos había supuesto seguridad jurídica y un enorme incremento de su valor: en Balcó de la Penya el precio del $\mathrm{m}^{2}$ pasó de 600 a 5.000 pesetas tras la aprobación del PGOU; incrementos incluso superiores, de entre 10 y 12 veces, se produjeron en parcelaciones ilegales del entorno de Zaragoza (Betrán, \& Franco, 1994, 124).

El PGOU de 1994 clasificó como urbanas no sólo las parcelas con edificación ${ }^{3}$ sino también todas las vacías, yendo mucho más allá de lo admisible legalmente pues Calderona, Vidriera y sobre todo Balcó de la Penya tenían edificados menos de 2/3 de su superficie, el mínimo exigido por el artículo 21 del Reglamento de Planeamiento de 1978 para su clasificación como urbano. Esto ha permitido un notable e injustificado crecimiento posterior de los núcleos de origen ilegal, especialmente Balcó de la Penya con muchas parcelas vacías y una privilegiada localización en la ladera oriental del Alt de la Redona; en 2019 hay un 48\% más de parcelas con edificaciones que en 1994 (Tabla 1). Pero todavía ha sido mayor el incremento de viviendas, que hoy son 414, casi el doble que al aprobarse el PGOU, porque éste permitió la construcción de adosados en algunas zonas ${ }^{4}$.

Tabla 1. Parcelas con edificaciones en los núcleos de origen ilegal en el PGOU de 1994 y en 2019. Fuente: Sede electrónica del Catastro: visualizador de inmuebles y visor cartográfico. Elaboración propia.

\begin{tabular}{|l|c|c|c|c|c|c|}
\hline \multirow{2}{*}{ Núcleos de origen ilegal } & \multicolumn{3}{|c|}{1994} & 2019 & \multicolumn{2}{c|}{ Incremento 1994-2019 } \\
\cline { 2 - 7 } & Urbanas & Edificadas & \% Edificadas & Edificadas & Número & $\%$ \\
\hline Balcó de la Penya & 107 & 29 & 27,1 & 76 & 47 & 162,1 \\
\hline Calderona & 95 & 55 & 57,9 & 74 & 19 & 34,5 \\
\hline Camí del Convent & 72 & 47 & 65,3 & 62 & 15 & 31,9 \\
\hline Camí de la Costera & 17 & 13 & 76,5 & 15 & 2 & 15,4 \\
\hline Clot d'Oliver & 46 & 30 & 65,2 & 37 & 7 & 23,3 \\
\hline Pla de la Venta & 54 & 33 & 61,1 & 43 & 10 & 30,3 \\
\hline Vidriera & 54 & 31 & 57,4 & 45 & 14 & 45,2 \\
\hline Total & 445 & 238 & 53,5 & 352 & 114 & 47,9 \\
\hline
\end{tabular}

El PGOU de 1994 consolidó así de manera irreversible unos núcleos residenciales carentes de los requisitos de un espacio urbano y cuya localización no venía determinada por un plan urbanístico sino por decisiones particulares carentes de lógica territorial. El resultado es

3 Se consideran también como "edificadas" las parcelas con construcciones destinadas a usos diferentes al de vivienda: almacenamiento, industrial...

4 En el pequeño núcleo de Camí de Convent-3 sólo había 5 casas en 1983 y hoy tiene 64 apartamentos adosados más en las 3 parcelas que estaban vacías; en Pla de la Venta hay otros 24 adosados y 14 en Balcó de la Penya. 
un suelo urbano formado por un continuo alargado e informe de chalets y adosados de una punta a otra del municipio (Figura 3).

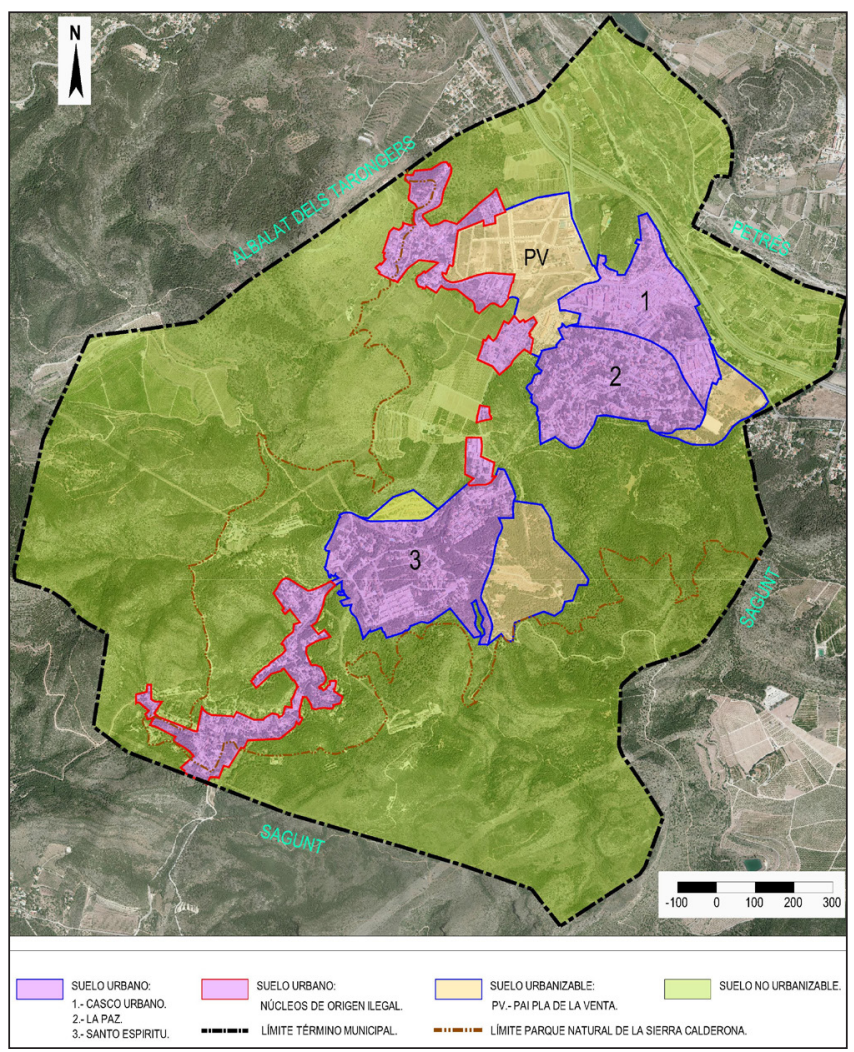

Figura 3. Clasificación del suelo en el PGOU de Gilet de 1994. (Se ha incluido el límite externo del Parque Natural de la Sierra Calderona aprobado en 2002). Elaboración E. Burriel y R. Zamorano.

\section{La inviabilidad de la regularización por la planificación urbanística}

La incapacidad del planeamiento, observada en Gilet, para reconducir las parcelaciones ilegales a una ordenación adecuada y eliminar los problemas que acarrean es general en toda España. No ha sido posible casi nunca ni por la vía de la restauración de la legalidad mediante la eliminación de lo construido irregularmente ni por la de su regularización como suelo urbano o urbanizable previa modificación del plan urbanístico.

La demolición de lo edificado ilegalmente rara vez se ha decretado y menos aún ejecutado (Olmedo, 2016, 3). Las pocas excepciones están casi siempre en espacios naturales protegi- 
dos o en terrenos de dominio público y han necesitado largos procesos judiciales hasta el Tribunal Supremo; Cantabria es una de las regiones con ejemplos más sonados (Delgado, 2011).

Tampoco ha dado resultado la opción de la reclasificación directa como suelo urbano a pesar de no disponer de los servicios e infraestructuras legales, unas veces sin condicionarla a su ejecución y otras postergando ésta al desarrollo de un planeamiento derivado casi nunca realizado; más excepcional ha sido la reclasificación como suelo urbanizable. Además del caso analizado de Gilet en la Comunidad Valenciana, hay ejemplos en Aragón (Betrán, \& Franco, 1994, 108), Cataluña (Nel·lo, 2011a, 88), Andalucía (Olmedo, 2016, 3) o Canarias (Parreño, 2006, 284).

La situación más frecuente ha sido el mantenimiento de los núcleos de viviendas ilegales en suelo no urbanizable, que se han consolidado por la inacción cuando no complicidad de las administraciones. Éstas han intentado bastante tiempo después su regularización, para la que prácticamente todas las leyes urbanísticas autonómicas contienen disposiciones específicas ${ }^{5}$.

Algunas Comunidades Autónomas sólo admiten la reclasificación a suelo urbano o urbanizable previo cumplimiento por los parcelistas de las obligaciones urbanísticas. Pero con frecuencia (Aragón, La Rioja, Extremadura, Madrid) han ido estableciendo procedimientos especiales para facilitar la regularización que, a pesar de que suelen suavizar, poco o mucho, los estándares urbanísticos, no parecen haber dado resultado; la Junta de Extremadura no ha aprobado todavía la regularización de ninguna urbanización ilegal (Jiménez Barrado, 2018, 516). Modificaciones legislativas recientes en algunas CC. AA. incluso parecen tender a favorecer la urbanización y edificación en el medio rural (Jiménez Barrado, et. al., 2017, 85-87).

Otras Comunidades Autónomas (Andalucía, Baleares, Canarias, Castilla y León, Comunidad Valenciana) han ofrecido la posibilidad de consolidar estos núcleos en suelo no urbanizable mediante figuras especiales de "asentamientos en suelo rural" - $\mathrm{u}$ otras denominaciones similares- pero limitando su expansión y exigiendo la ejecución de algunas infraestructuras para minimizar el impacto sobre el medio y mejorar la calidad de vida. Sin embargo, tampoco esta posibilidad excepcional parece haber funcionado (Olmedo, 2016, 3).

Una prueba de la ineficacia de los intentos de regularización es la presencia en las sucesivas leyes urbanísticas de las CC. AA. de las mismas o parecidas disposiciones para conseguirlo. Un ejemplo muy claro es la Comunidad Valenciana: la Ley 4/1992 sobre Suelo No Urbanizable permitía en los dos años siguientes reclasificar las urbanizaciones desarrolladas "al margen de la legalidad", pero tenían que "asumir las cargas urbanísticas" legales (Disposición Transitoria Segunda); 12 años después en la Ley 10/2004 del Suelo No Urbanizable aparece la posibilidad de "núcleos de viviendas consolidados" en suelo no urbanizable implantados "al

5 Se ha consultado directamente toda la legislación aprobada por las diversas CC. AA. Un amplio análisis de la regulación autonómica de las urbanizaciones ilegales se puede ver en Jiménez Barrado, 2018, 153-219. 
margen de los procesos formalizados de urbanización y edificación" que deben "minimizar su impacto territorial", a los que sólo se les exige un sistema de depuración de vertidos, recogida regular de residuos sólidos y adecuada conexión con la red viaria (Disposición Transitoria Cuarta); esta figura se mantiene con una regulación mucho más detallada en la Ley 5/2014 de Ordenación del Territorio, Urbanismo y Paisaje (artículos 210-212) y se repite en la Ley 1/2019 de modificación de la Ley 5/2014. Pero después de 27 años y 4 leyes todavía no se ha dado ni un solo caso de regularización ${ }^{6}$.

Algunos autores atribuyen el fracaso generalizado de los intentos de regularización de las parcelaciones ilegales a la pasividad administrativa, en buena medida por electoralismo (Martín Fernández, 2011, 118). Pero otros coinciden con la posición de este artículo en que la causa estaría en la ilegalidad sustancial de este proceso, que "no tiene nada que ver con la producción de suelo urbano" establecida en nuestro sistema urbanístico, por lo que éste no puede regularizarlo; e insisten en la necesidad de buscar fórmulas más flexibles y una gestión adaptada a estas situaciones (Herce, 1997).

En esa línea de que la clave está en resolver los problemas de gestión y financiación se planteó la Llei 3/2009, del 10 de març, de regularització i millora d'urbanitzacions amb dèficits urbanístics de la Generalitat de Cataluña. Implicaba a propietarios, ayuntamientos y gobierno autonómico y establecía ayudas económicas a los municipios para la elaboración de los instrumentos que tenían que tramitar y préstamos subvencionados a los propietarios con rentas insuficientes para costear las obligaciones urbanísticas, ambas medidas imprescindibles para el éxito de la regularización (Nel·lo, 2011a, 91-95). En el primer año de vigencia se emprendieron actuaciones en 99 urbanizaciones (Sindic de Greuges, 2013, 2); pero tras el cambio de signo político de la Generalitat la ley presupuestaria de 2011 eliminó las ayudas lo que paralizó por completo la aplicación de la ley.

La ilegalidad original condiciona de tal modo el planeamiento posterior que hace muy difícil que éste pueda reconducirla a una adecuada ordenación territorial. Se mantiene así una localización desordenada de los espacios residenciales que, además de hipotecar la calidad del territorio, está en la base de casi todos los otros problemas: impactos ambientales, mala calidad urbanística, mayores costes económicos para la colectividad y conflictos sociales y políticos.

\section{IMPORTANTES IMPACTOS AMBIENTALES}

La localización inadecuada y el déficit de infraestructuras básicas, ambos derivados de la ilegalidad original, han dado lugar a significativos impactos ambientales que perduran hasta hoy y la mayoría son irreversibles.

6 En la Consellería de Vivenda, Obres Públiques $i$ Vertebració del Territori de la Generalitat Valenciana sólo hay 6 expedientes en tramitación y ninguno se ha llegado aún a aprobar. 
La principal afección al medio es la ocupación de espacios de valor natural o paisajístico. Cuando en 2002 se aprobó el Parque Natural de la Sierra Calderona su delimitación en el término de Gilet vino condicionada por las edificaciones ilegales preexistentes que obligaron a fijar como límite inferior la cota 200, dejando fuera zonas que constituían su continuidad natural y podían actuar como áreas tampón; y a pesar de ello aún quedaron dentro del espacio protegido unas cuantas viviendas de Calderona y Balcó de la Penya, como se observa en las Figuras 2 y 3.

Los núcleos de Calderona, Vidriera y Clot d'Oliver se desarrollaron en la vertiente de umbría de la sierra y en el entorno del monasterio de Sant Espírit, las zonas de mayor importancia ecológica del municipio según la Memoria del PGOU. Pero también las dos urbanizaciones de origen legal, "Santo Espíritu" y "La Paz", están ubicadas en parajes en los que hoy no se aceptaría que el planeamiento les asignara un uso residencial, (Burriel, 2018, 32-35).

Terrenos de interés colectivo por su valor ambiental han pasado a ser de uso privado al haber quedado incluidos dentro de las parcelas. En muchas de éstas la superficie no construida ha sido también antropizada, cubriéndola con cemento o piedras o decorándola con objetos diversos de mal encaje en el paisaje en el que se ubican, como grandes tinajas, rocallas, maquetas de monumentos, enanitos de Blancanieves y otras figuras Disney bastante kitsch (Figura 4). También es habitual la plantación en los jardines de vegetación alóctona cuya posterior expansión por el entorno altera el ecosistema.

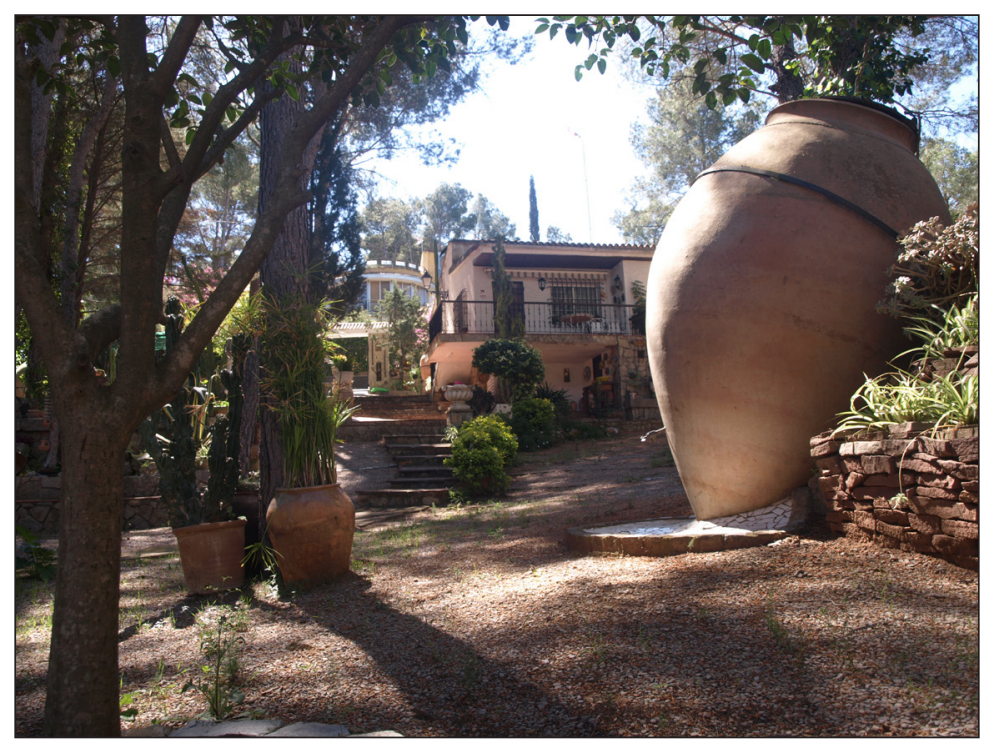

Figura 4. Parcela entre pinos en la que la superficie no construida ha sido completamente antropizada (Clot d'Oliver). Fotografía E. Burriel, junio 2017. 


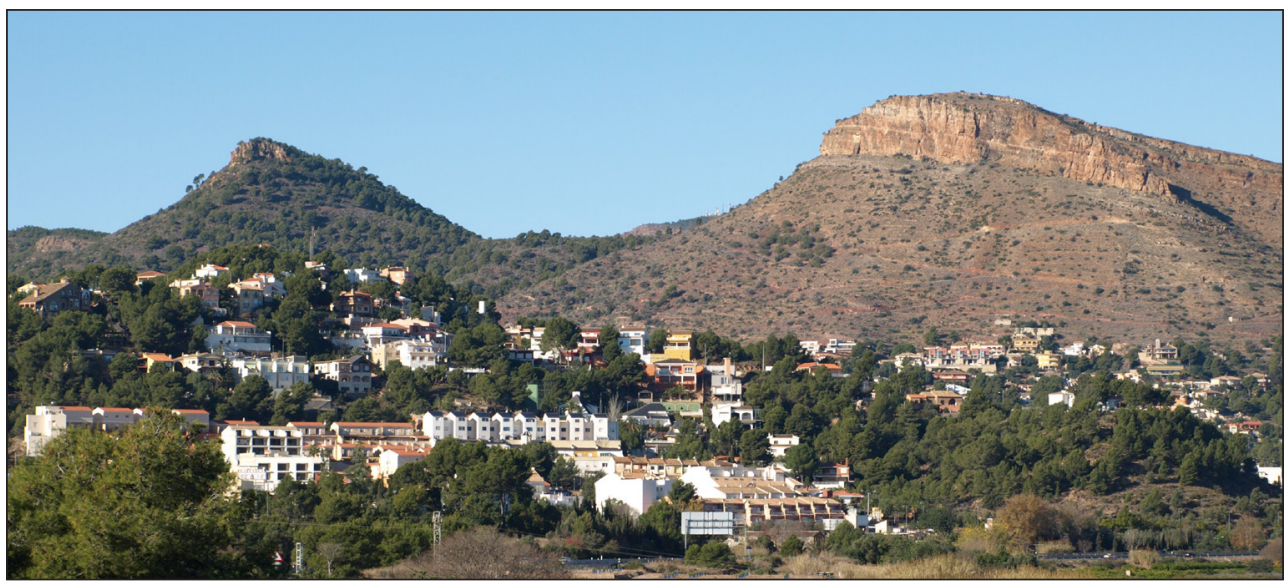

Figura 5. Impacto paisajístico de La Paz y Balcó de la Penya sobre el perfil de la sierra Calderona. Deforestación del Alt de la Redona por el incendio de 2014. Fotografía E. Burriel, diciembre de 2017.

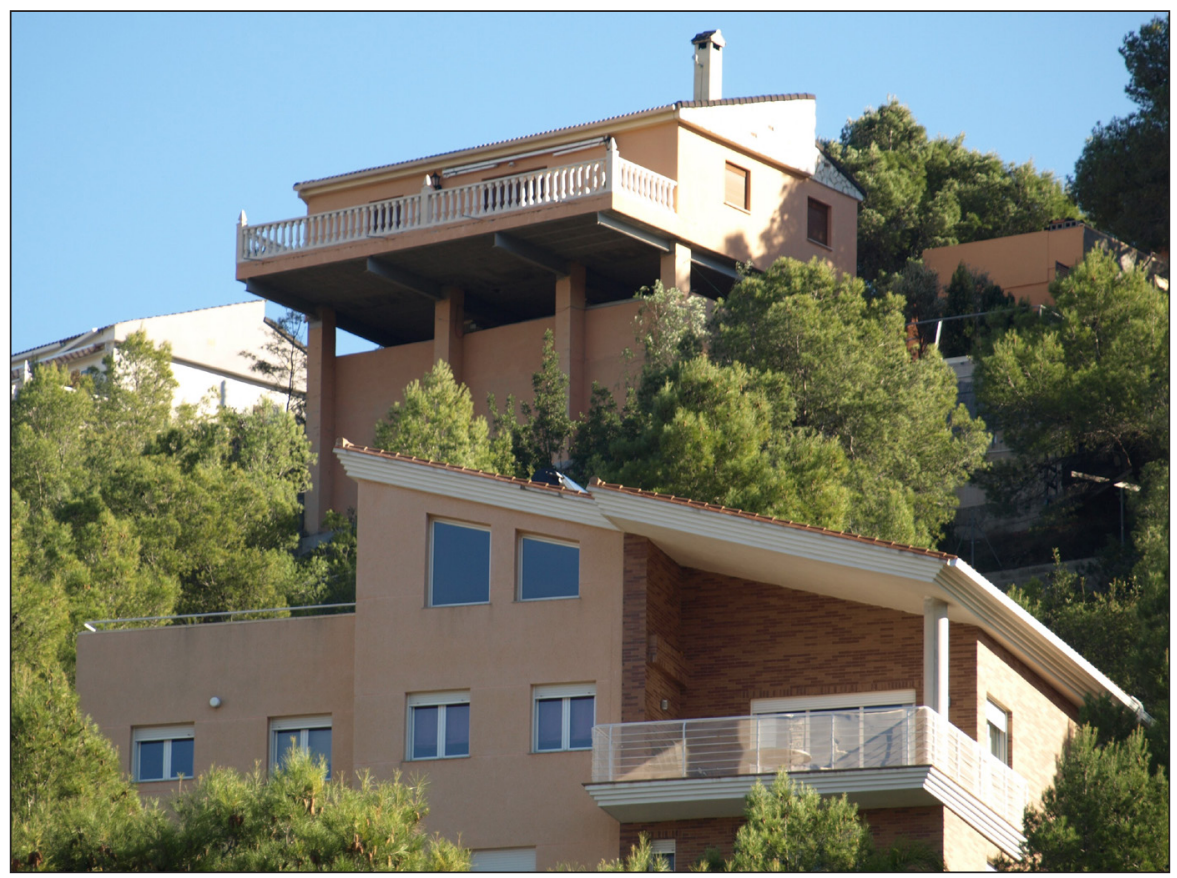

Figura 6. Casa elevada en altura sobre pilares a causa de la fuerte pendiente (La Paz). Fotografía E. Burriel, diciembre de 2017. 
La ubicación de varios núcleos en zonas de fuerte pendiente ha supuesto un importante impacto paisajístico, sobre todo en Balcó de la Penya y La Paz cuyas edificaciones se anteponen al singular perfil de la sierra Calderona "como de un oleaje rompiente inmovilizado" visto desde la llanura costera y el valle del Palancia (Pérez Puchal, 1968, 18) (Figura 5). La degradación del paisaje se acentúa porque la gran inclinación de algunas parcelas obliga, para disponer de suficiente superficie útil, a construir casas muy altas mediante elevados pilares que dejan huecas varias plantas del edificio (Figura 6). Los fuertes desniveles llevan también a desmontar laderas para poder construir las casas y a levantar altos muros para sostener el terreno y proteger de la erosión a las viviendas (Figura 7) o al viario; muros cuyo derrumbe no es infrecuente (Figura 8).

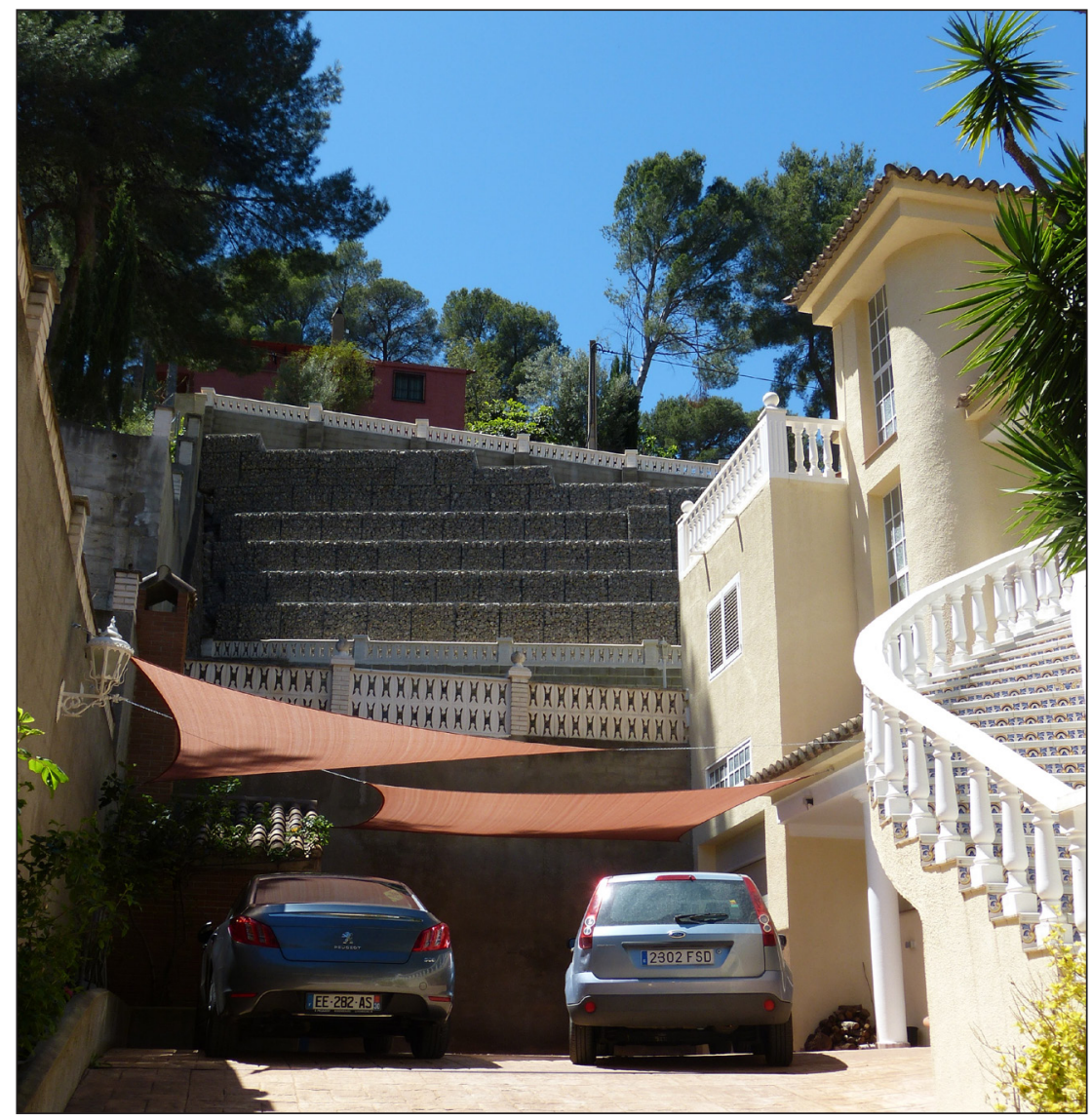

Figura 7. Elevado muro para contener la ladera y poder construir la casa en una parcela de gran desnivel (Clot d'Oliver). Fotografía E. Burriel, abril de 2019. 


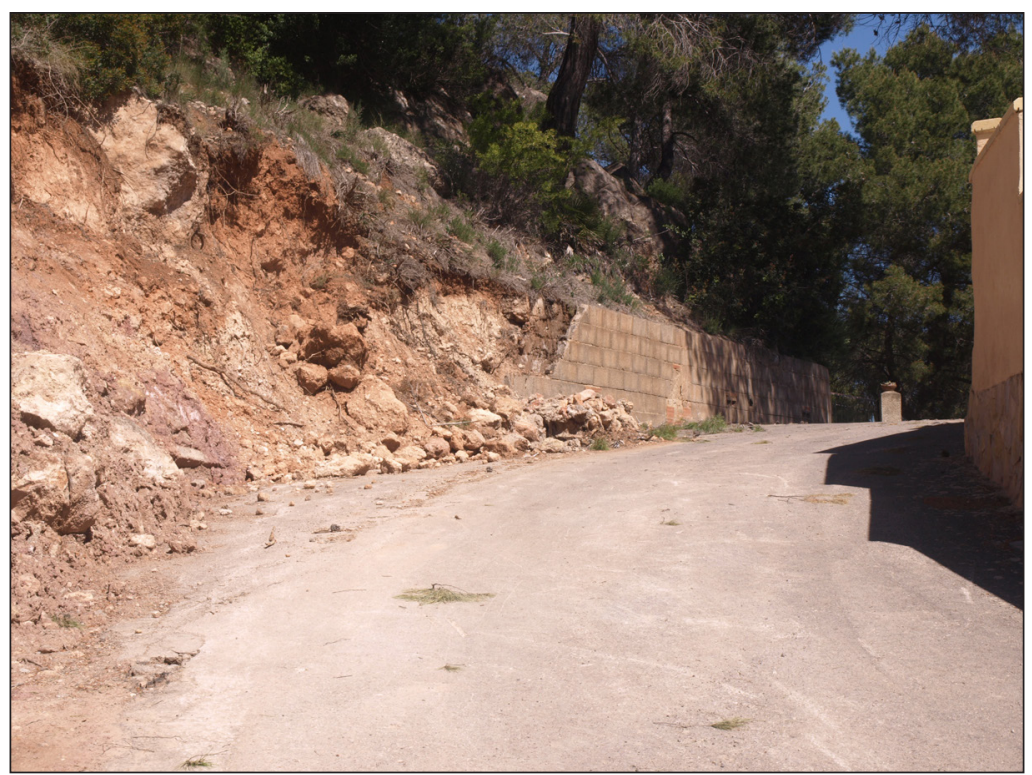

Figura 8. Derrumbe de un muro de protección del viario en una zona con mucha pendiente (Clot d' Oliver). Fotografía E. Burriel, junio de 2017.

La localización dispersa y desordenada de las viviendas ilegales por todo el término ha supuesto también el consumo indiscriminado de un recurso natural escaso y valioso como es el suelo, lo que además hipoteca las posibilidades futuras de un municipio tan pequeño. Los tradicionales bancales de algarrobos y olivos han desaparecido casi por completo, con la consiguiente pérdida de un paisaje agrario secular y singular que podía haberse mantenido en las zonas de mucha pendiente, inadecuadas para la función residencial.

Otros impactos derivan de la carencia o déficit de infraestructuras urbanísticas. El más importante es el elevado riesgo de contaminación del suelo por la existencia de un sinnúmero de pozos ciegos, construidos además sin mucho rigor ni control, o por el vertido directo al cauce de los barrancos ${ }^{7}$; los técnicos municipales ya advertían de ello en $1983^{8}$. Incluso la torre de diez plantas de la urbanización de Santo Espíritu, ilegal en su origen (Burriel, 2018, 36), vertía a una fosa séptica que terminó rebosando para desagradable sorpresa del restaurante de la planta baja. La Confederación Hidrográfica del Júcar amenazó con una elevada multa por la falta de depuración de las aguas residuales de Balcó de la Penya y Camí

7 Como se podía observar en una vivienda de Clot d'Oliver antes de que recientemente se conectara al colector general situado bajo el lecho de ese barranco.

8 Informe mecanografiado de 13-1-1983 (Archivo del ayuntamiento de Gilet) 
del Convent-1 (Levante, 2012); pero esta sanción recaería en primera instancia sobre el ayuntamiento y no sobre los parcelistas responsables del problema.

La dispersión de los núcleos y la deficiencia del viario impiden la recogida diaria de los residuos sólidos todo el año y hace que los contenedores, situados casi siempre en la entrada de cada urbanización, resulten insuficientes, sobre todo tras fines de semana o festivos, con la consecuente dispersión de basura por el entorno que ha llevado a rodearlos con un vallado de madera. Algunas parcelas no construidas se utilizan como vertederos ocasionales de todo tipo de objetos lo que contribuye a acentuar la degradación del medio.

La localización de muchas de las casas en zonas forestales -como se puede observar en las Figuras 2 y 10- supone un problema importante en caso de incendio, frecuente por las condiciones climáticas y el predominio del pinar y del matorral ${ }^{9}$. El riesgo aumenta cuando la evacuación ha de hacerse por una pista estrecha y de fuerte pendiente (zona alta de Clot d'Oliver) o por calles que terminan en fondo de saco o en un barranco (La Monedera y El Garbí en Calderona). La intensificación de la actividad humana en áreas boscosas que acarrean estos núcleos residenciales incrementa la probabilidad de incendio; el de 2014 se generó al parecer por una imprudencia en una vivienda aislada cercana a Balcó de la Penya ${ }^{10}$.

Otros problemas más puntuales derivan de la utilización como calle de un barranco de corto recorrido como la que lleva el expresivo nombre de "el Barranquet" en Camí del Convent-1 (Burriel, 2018, 49-50), o del cegado de pequeños cauces para la construcción de algunas casas.

Las viviendas ilegales desarrolladas hace casi medio siglo han dejado en el territorio de Gilet una huella ambiental profunda y difícilmente reversible. La contaminación de los suelos por los vertidos de aguas residuales puede desaparecer en unos años porque la red de alcantarillado está por fin construida en unos núcleos y en proyecto en los demás. Pero con la consolidación de estas urbanizaciones en localizaciones inadecuadas no hay solución para la destrucción y deterioro de espacios naturales valiosos, el impacto paisajístico, la pérdida del recurso suelo y del terrazgo agrícola o el riesgo de incendio.

Impactos ambientales similares a los observados en Gilet están presentes en todos los territorios que conocieron este tipo de parcelaciones como se indica, aunque de manera casi siempre muy genérica, en la literatura académica (Hermosilla, 1992, 108; Betrán, \& Franco, 1994, 107; Fajardo, 2003, 21-22; Parreño, 2006, 236; Nel·lo, 2011a, 82; Jiménez Barrado, \& Campesino, 2017, 262).

9 Desde el inicio de las viviendas ilegales en los años 60 ha habido incendios importantes en 1979, 1994 y 2014. 10 Se inició por las chispas de una sierra mecánica de un taller de escultura situado en dicha vivienda; en el entorno se localizaron también numerosas colillas. 


\section{Persistencia De Déficits urbanísticos}

Los núcleos ilegales de Gilet surgieron carentes de las infraestructuras y servicios propios de un espacio urbano: sin alcantarillado, sin agua o abasteciéndose de pozos agrarios sin garantías de potabilidad, sin electricidad, con un viario de mala calidad, sin zonas verdes ni dotaciones públicas (Burriel, 2018, 41-43 y 49-50). Esta situación se ha prolongado durante décadas por la negativa de los propietarios a hacerse cargo de su ejecución. Aunque poco a poco ha ido mejorando, todavía hoy existen déficits importantes, algunos de casi imposible solución.

La conexión a la red municipal de agua potable se consiguió pronto, en los años 80, financiada por los parcelistas (Calderona, Vidriera y Clot d'Oliver) o por el Ayuntamiento cuando era fácil por la cercanía al casco urbano (Pla de la Venta, Camí del Convent y Camí de la Costera); pero en Balcó de la Penya aún procede de un pozo agrícola. La electricidad no llegó hasta los años 90, una vez que la concesión de licencia de segunda ocupación a partir de 1988 les permitió contratar el servicio; salvo Balcó de la Penya que dispuso de ella casi desde su inicio a pesar de la ilegalidad de la parcelación ${ }^{11}$.

Pero sólo financiaron estas infraestructuras indispensables y de uso privado en el interior de su parcela, negándose a las de interés colectivo situadas fuera ella: pavimentado de calles, aceras, alumbrado público, alcantarillado y renovación de la muy deficiente red interna de agua. La mayoría de los propietarios, como se explicó, mantuvieron esta negativa tras la clasificación como suelo urbano en el PGOU de 1994, incumpliendo su compromiso con el ayuntamiento.

El gobierno local intentó durante años resolver la situación mediante el diálogo, sin resultado porque se topó con el rechazo a pagar las cargas urbanísticas a que estaban obligados. Esto fue retrasando la actuación en los núcleos que sí estaban dispuestos a cumplir su compromiso (Vidriera, Clot d'Oliver y Pla de la Venta), hasta la legislatura 2007-2011 en que se realizó en ellos el pavimentado de las calles, el alcantarillado y la renovación de la red interna de agua, costeados por los parcelistas mediante contribuciones especiales; y se consiguió también la aceptación de Calderona, cuyas obras se acabaron en 2015. El alumbrado público se abordó más tarde, pero en este caso financiado por la Diputación de Valencia en sus Planes de Obras y Servicios; está terminado en Pla de la Venta y Vidriera, en obras en Clot d'Oliver y aprobado en Calderona.

En 2019, casi medio siglo después del inicio del proceso, Balcó de la Penya, Camí del Convent-1 y Camí de la Costera, que reúnen casi la mitad de las parcelas ilegales, siguen sin alcantarillado, ni alumbrado público, ni red interna de agua en condiciones; y sus calles, estrechas y sin aceras, son de tierra y con la lluvia se convierten en barrizales y se deterioran (Figura 9). Estas carencias parece que están en camino de resolverse porque por fin han

11 Gracias al parecer a la relación con Hidroeléctrica Española de uno de sus promotores, instalador eléctrico. 
aceptado financiar estas infraestructuras; aunque para ello la Consellería d'Obres Públiques, que ya se hizo cargo en 2002 del depósito de agua de Balcó de la Penya, ha tenido que comprometerse a ejecutar también la tubería para su conexión con la red municipal. Éste ha sido durante años el obstáculo para un acuerdo, con la paradoja de que el ayuntamiento tenía que gastar unos 36.000 euros cada año en la reparación de las continuas roturas de la deficiente red interna hecha por los promotores.

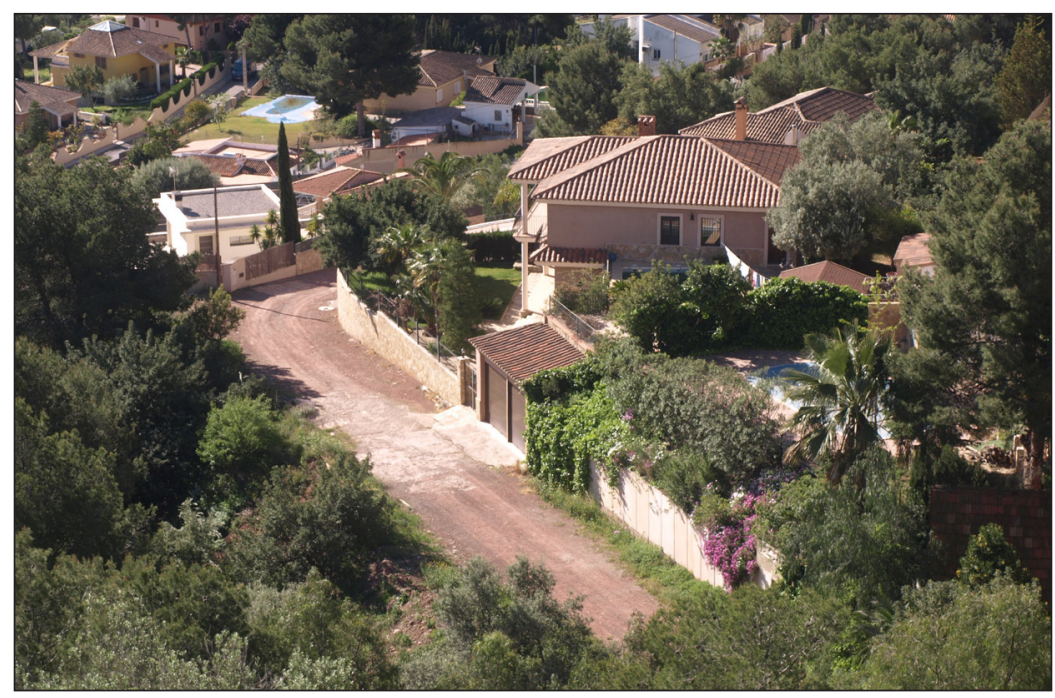

Figura 9. Calle de tierra, sin aceras, alumbrado ni alcantarillado. Contraste con la calidad y tamaño de los chalets (Balcó de la Penya). Fotografía E. Burriel, junio de 2017.

Por otro lado, su realización a posteriori resulta mucho más compleja y costosa por la dispersión territorial, el alejamiento de las redes generales de servicios, las fuertes pendientes y la mala accesibilidad (Nel·lo, 2011a, 88), además de por la parcelación y construcción de las viviendas sin previo planeamiento, urbanización o proyectos técnicos ${ }^{12}$.

También persisten deficiencias en el viario, tanto el de acceso como el interno de los núcleos, algunas de imposible solución. El camino al Balcó de la Penya y la vía pecuaria que lleva a Vidriera, Clot d'Oliver y Calderona se asfaltaron en la segunda mitad de los 80 pero

12 La ejecución del alcantarillado en Balcó de la Penya va a exigir un absurdo y costoso bombeo a pesar de que su desagüe debería ser fácil por la fuerte inclinación de las parcelas; pero como no se hizo a la vez que la parcelación, ahora muchos propietarios no conceden servidumbre de paso a las casas de la parte alta. También será costoso el de Camí de la Costera porque exige o un bombeo al colector del PAI del Pla de la Venta situado a mayor altura o un colector nuevo y de mucha mayor longitud siguiendo la inclinación del terreno. 
sin modificar su trazado que por su anchura insuficiente, algunas curvas cerradas y tramos de bastante pendiente no resulta muy adecuado para el tráfico actual. A las viviendas de la parte alta de Clot d'Oliver se accede por una pista estrecha y con muy fuertes pendientes, problemática para la evacuación en un incendio u otra situación de riesgo. Sólo los accesos a Pla de la Venta y a Camí de la Costera son hoy vías anchas, bien asfaltadas, con alumbrado público y aceras, porque forman parte del desarrollo del suelo urbanizable del contiguo PAI del Pla de la Venta.

La mayoría de las calles siguen siendo estrechas, sin aceras y con pendientes excesivas; y su adecuación resulta casi siempre imposible por la parcelación ilegal previa, las condiciones físicas del terreno y la construcción de muchas de las casas hasta el borde mismo de la propiedad (Figuras 10 y 11).

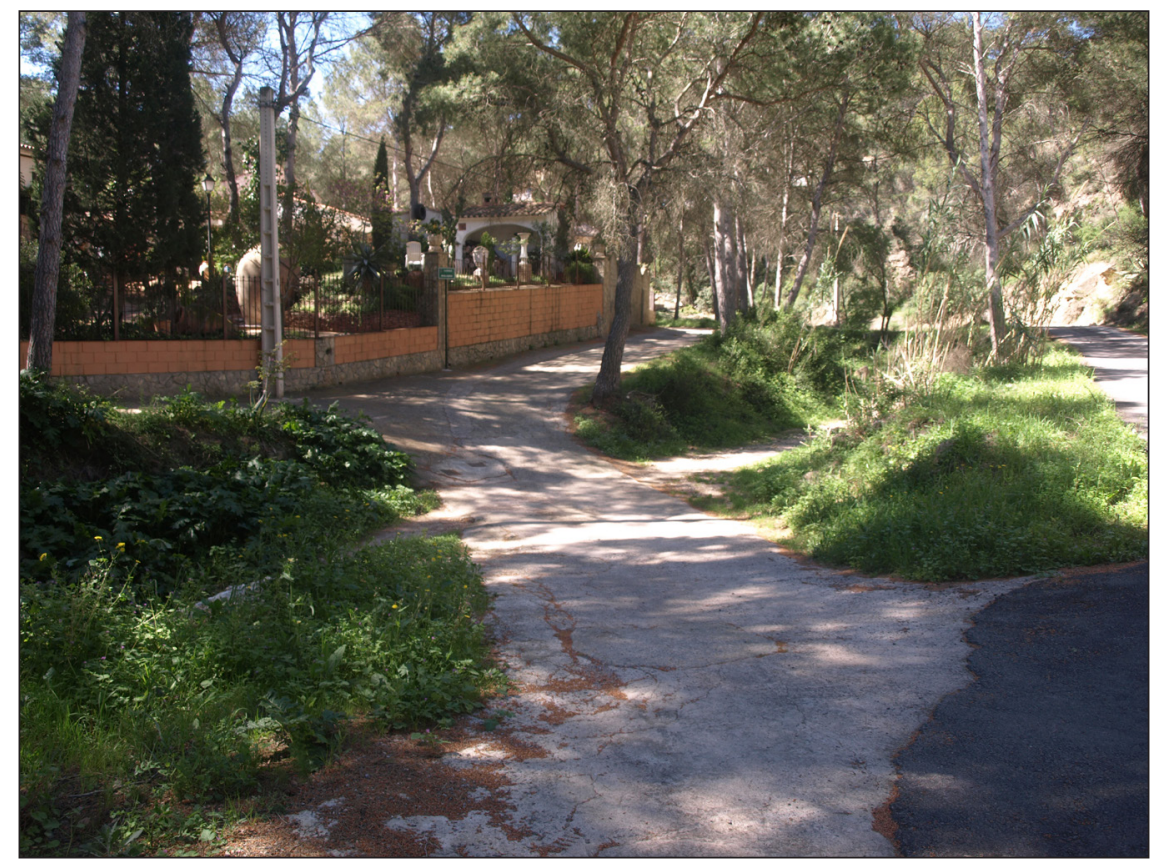

Figura 10. Viario estrecho, sin aceras, mal pavimentado y que cruza un barranco por un badén (Clot d'Oliver). Fotografía E. Burriel, junio de 2017. 


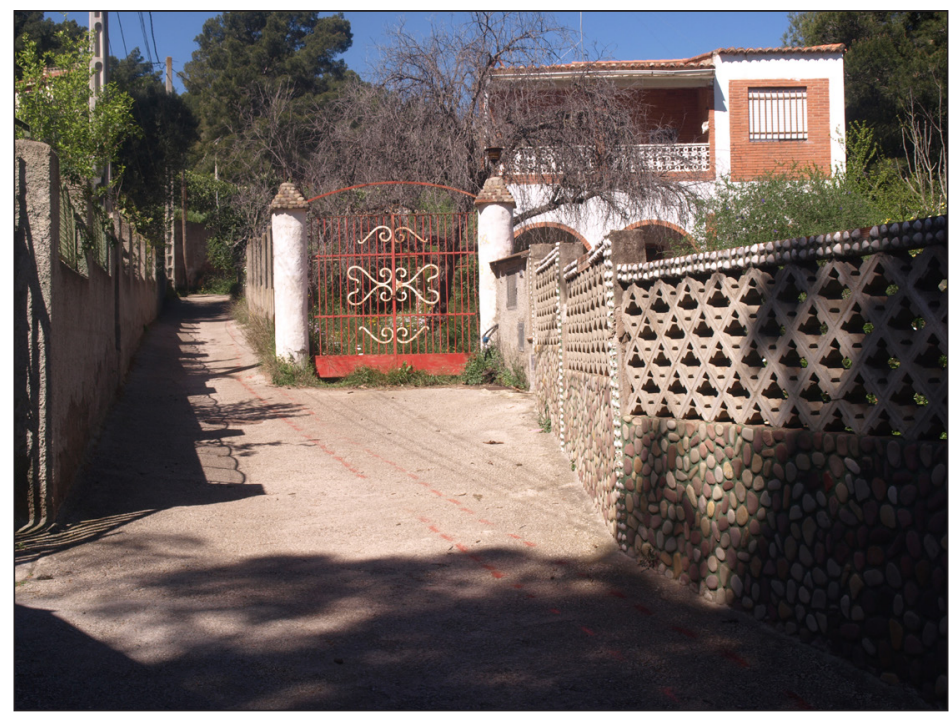

Figura 11. Calle muy estrecha por la que no puede pasar una ambulancia ni un vehículo de bomberos (Vidriera). Fotografía E. Burriel, junio de 2017.

El PGOU de 1994 estableció la superficie mínima legal de zonas verdes. Las correspondientes a Calderona, Vidriera y Clot d'Oliver se situaron en parcelas de propiedad municipal. Las de Pla de la Venta, Camí de la Costera y Camí del Convent se adscribieron al suelo urbanizable del PAI del Pla de la Venta. Pero las de Balcó de la Penya tuvieron que localizarse en parcelas privadas y la exigencia de su expropiación por los afectados ha terminado con la condena judicial al ayuntamiento a abonar casi 1 millón de euros; esto le ha obligado a endeudarse con un préstamo a 10 años que supone una pesada losa para las arcas de un municipio tan pequeño.

No se les exigió la obligada cesión de suelo para servicios y equipamientos públicos (docentes, sanitarios, culturales, asistenciales, deportivos...). Su ausencia preocupaba poco inicialmente a unos propietarios que sólo acudían a estas viviendas en Pascua y en verano y que tampoco disponían entonces de esas dotaciones en sus barrios de residencia habitual. La no excesiva distancia al casco urbano y el escaso número de residentes permanentes explican que esta carencia no haya planteado aún problemas significativos.

También ha mejorado bastante el tamaño y la calidad de muchas viviendas a la par que lo hacía la situación económica de algunos parcelistas iniciales y que fueron llegando nuevos propietarios con mayor capacidad adquisitiva. En 2019 sólo subsisten la mitad de las casas más pequeñas y elementales que había en 1983 (Burriel, 2018, 50-53) y por lo general están 
abandonadas o en venta ${ }^{13}$. Sin embargo, la mayoría de las antiguas -a pesar de la ampliación de muchas de ellas construyendo un piso superior o habilitando la planta baja inicialmente hueca- son de estructura muy simple, materiales de poca calidad, instalaciones eléctricas o sanitarias deficientes y escasa confortabilidad; por ello resultan poco adecuadas para su uso como vivienda habitual. Con ellas conviven hoy en Gilet, como en las urbanizaciones de origen ilegal de otros territorios (Madrazo y Mato, 2002, 408), numerosas casas de nueva construcción de mayor tamaño y de estructura y diseño moderno que contrastan vivamente con las deficiencias urbanísticas del espacio en el que se ubican (Figuras 9 y 12).

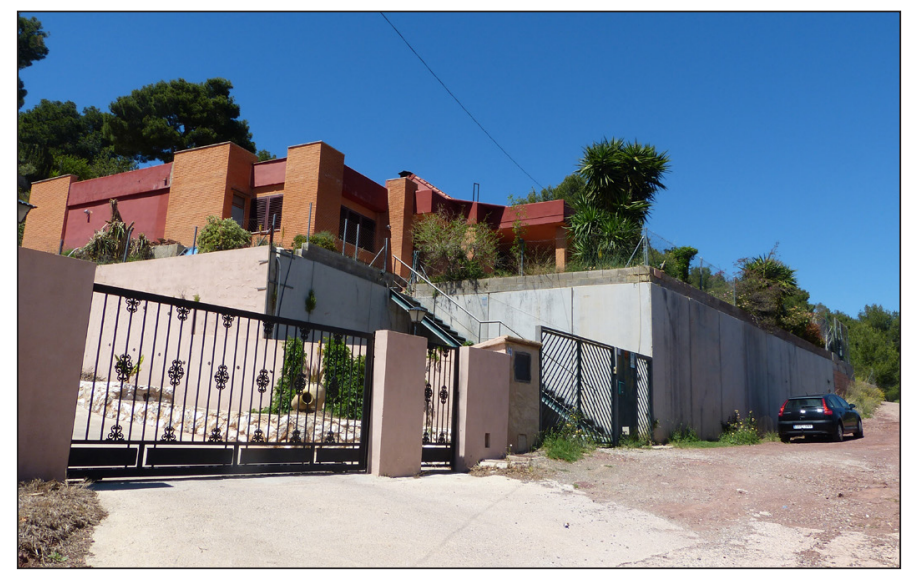

Figura 12. Casa de calidad y diseño moderno que contrasta con la deficiente urbanización del espacio público de su entorno (Balcó de la Penya). Fotografía E. Burriel, abril de 2019.

Estos importantes déficits que persisten en Gilet están presentes también en todos los territorios donde se desarrollaron parcelaciones ilegales. En Cataluña más de la mitad de las urbanizaciones, legales o no, carecían en 2011 de uno o más de los servicios básicos exigidos en suelo residencial (Nel-lo, 2011a, 87-88). En la Comunidad Valenciana, miles de chalets de Llíria y de la urbanización de Calicanto, que se extiende por 3 municipios, no tienen alcantarillado, lo que ha afectado a la potabilidad del agua de que se abastecen (Levante, 2017, noviembre 22). En el entorno de Zaragoza el riesgo de contaminación de los acuíferos ha sido objeto de numerosas denuncias del SEPRONA (Betrán \& Franco, 1994, 107). Las mismas carencias se dan en Andalucía (Fajardo, 2003, 19-21), Castilla-La Mancha (Madrazo \& Mato, 2002, 408) o Extremadura donde se subraya el llamativo contraste entre el ínfimo

13 En 1983 el "censo" de viviendas ilegales que realizó el Ayuntamiento recogía 49 casas de menos de $61 \mathrm{~m}^{2}$ de las que 8 tenían menos de $31 \mathrm{~m}^{2}$; en abril de 2019 éstas son 25 y 4 respectivamente (Dirección General del Catastro. Sede electrónica). 
nivel de equipamientos colectivos y la disponibilidad generalizada de piscinas privadas y jardines (Jiménez Barrado, 2018, 515) también observable en Gilet.

La persistencia casi medio siglo después de importantes deficiencias de infraestructuras y de carencia de equipamientos públicos es otra importante huella de las urbanizaciones desarrolladas al margen de la legalidad urbanística. Obedece también a la ilegalidad originaria que les permitió, al ahorrarse éstos y otros costes, acceder a su deseo de una vivienda secundaria; y luego se convierten en factor decisivo de la imposibilidad de regularizar su situación jurídica (Nel·lo, 2011b, 240).

La negativa de los propietarios se mantiene porque la ejecución de las obras pendientes es muy $\operatorname{costosa}^{14}$ y porque ya han obtenido el principal beneficio, el aprovechamiento urbanístico, y lo que podrían conseguir no les parece que merezca tan alto precio. Se refuerza con el paso del tiempo porque las viviendas se consolidan por la inacción de la administración -sea por complicidad con un proceso que sus vecinos consideraban beneficioso o sea por mantener la paz social- o por su poca eficacia al tener que enfrentarse al "misil de los hechos consumados" con "la tortuga del derecho administrativo" (Herce, 1997, 121).

Esto les ha dado una sensación de impunidad (Jiménez Barrado et al., 2017, 89) y de derechos adquiridos -más aún cuando como en Gilet se han reclasificado como suelo urbano- $y$ de que el tiempo juega a su favor. Por ello no toman nunca la iniciativa de regularizar sus viviendas, pese a las esporádicas amenazas de la administración (Betrán, \& Franco, 1994, 111), y confían en que su presión constante y los perjuicios colectivos que ocasionan sus carencias acabarán consiguiendo que la comunidad se haga cargo de todo o parte de ellas.

\section{EsCASA CONTRIBUCIÓN ECONÓMICA DE LOS PROPIETARIOS Y ELEVADOS COSTES COLECTIVOS}

Los dueños de las viviendas de origen ilegal reclaman insistentemente a la administración la urbanización y los servicios de que carecen. Esta exigencia cobra más fuerza a medida que el paso del tiempo las ha ido consolidando de manera prácticamente irreversible (Betrán \& Franco, 1994, 107; Nel·lo, 2011b, 241-242) y que sus carencias originan problemas a la comunidad, como el ya señalado de la contaminación del acuífero por falta de alcantarillado. A ello se añade la escasa conciencia de su responsabilidad en los déficits que reclaman, acentuada porque muchos de ellos no son los propietarios iniciales y desconocen la ilegalidad originaria de unas parcelas que, en no pocos casos como sucede en Gilet, adquirieron cuando ya eran suelo urbano. Es muy expresiva la queja de la Presidenta de la Asociación de Vecinos de Calicanto, de Xiva (Valencia), ante la no aptitud para el consumo humano del agua del pozo de riego del que se abastecen, como si el problema no tuviera nada que ver con ellos: "Es vergonzoso que no haya alcantarillado. Tenemos pozos ciegos que acaban contaminando más" (Levante, 2017, noviembre 23).

14 Nel-lo $(2011 \mathrm{a}, 89)$ calcula unos costes de entre 21.000 y 38.000 euros por parcela. 
Pero como tampoco los presupuestos municipales tienen capacidad para afrontar las infraestructuras pendientes lo habitual ha sido la persistencia de los déficits, salvo que ante la presión vecinal alguna administración haya acabado haciéndose cargo de todo o parte de su coste. En el caso de Gilet, como ya se señaló, la Generalitat Valenciana ha financiado el colector general de aguas residuales y el depósito de aguas de Balcó de la Penya y se ha comprometido a la conexión de éste con la red municipal, la Diputación ha costeado el alumbrado público y el Ministerio de Agricultura dio ayudas para el asfaltado de algunos caminos de acceso. El ayuntamiento, por su parte, ha estado pagando cada año miles de euros para reparar las roturas de su red interna de agua y le ha costado casi 1 millón de euros la expropiación de las zonas verdes de Balcó de la Penya no cedidas como correspondía al hacer la parcelación.

Los propietarios de las viviendas ilegales suelen basar sus reclamaciones en la falsa creencia de que el pago de Impuesto de Bienes Inmuebles (IBI) como suelo urbano les igualaría en derechos con los demás vecinos y el municipio estaría obligado a proporcionarles todos los servicios; sin embargo, esto de ningún modo les exime de las obligaciones urbanísticas que no asumieron.

Por otro lado, los parcelistas ilegales contribuyen poco a los ingresos municipales. Por su ilegalidad original no cedieron al ayuntamiento ni el porcentaje legal del aprovechamiento urbanístico, ni las reservas de suelo obligatorias para viario, zonas verdes, servicios y equipamientos. Tampoco pagaron licencia de obras, ni el impuesto sobre el incremento del valor de los terrenos, ni el de solares no edificados; y su IBI, que tanto alardean de pagar, fue muy reducido mientras las casas estuvieron en suelo no urbanizable (García Lliberós, 1983, 52-54).

Además de haber contribuido menos, ocasionan unos gastos mayores porque las tasas que pagan por los servicios públicos (ciclo del agua, recogida de basuras, seguridad...) no cubren los costes de prestación y mantenimiento en urbanizaciones como éstas de muy baja densidad (Mur \& Clusa, 2011; Henry, 2007); lo que se acentúa en las ilegales por su dispersión territorial e inadecuadas condiciones topográficas.

En Gilet los camiones de recogida de residuos tienen que recorrer más de $12 \mathrm{~km}$. para atender a unos núcleos esparcidos por el término y con malos accesos; y aun así el servicio es deficiente -sólo 3 días por semana fuera del verano- dada la creciente población con residencia permanente. También es más costoso el servicio de agua y alcantarillado por la gran longitud de la red para atender a estos núcleos que aumenta aún más las pérdida ${ }^{15} \mathrm{y}$ por la necesidad de bombeo en algunas zonas; y lo mismo ocurre con el alumbrado público que necesita muchos puntos de luz. Dotar de una seguridad adecuada a estas viviendas unifamiliares, dispersas y alejadas del pueblo exigiría mucho personal y Gilet sólo dispone de tres policías para todos los turnos; el ayuntamiento se está planteando, otro gasto más, la instalación de cámaras en las vías de acceso a las urbanizaciones.

15 La eficiencia de la red de agua de Gilet es sólo de un 55\%. 
Y pese a todo esto los propietarios de las viviendas de origen ilegal se consideran mal atendidos por los ayuntamientos y les reclaman las infraestructuras y dotaciones de las que carecen -que debieron y deben pagar ellos- y acaban convirtiendo su exigencia en un problema político.

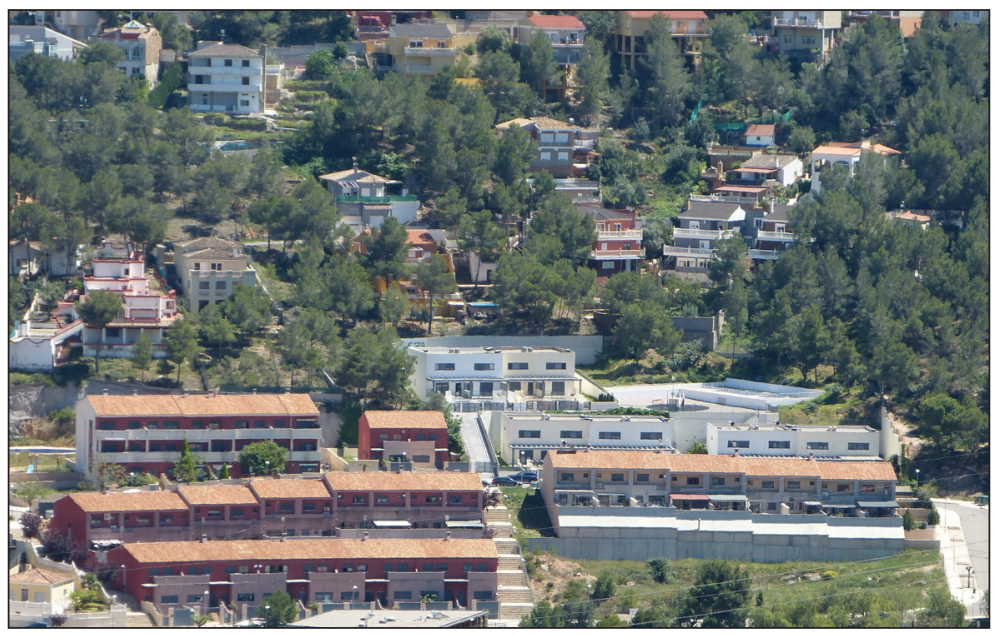

Figura 13. Alta densidad edificatoria en viviendas adosadas de la periferia del casco urbano (al oeste, en la ladera baja de la Paz). Fotografía E. Burriel, abril de 2019.

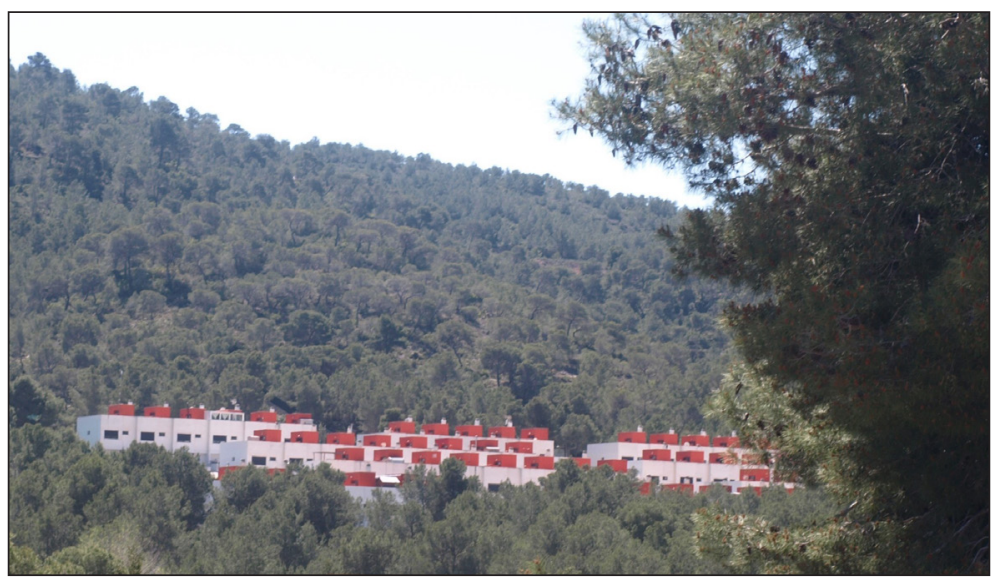

Figura. 14. Impacto paisajístico en la umbría boscosa de la sierra Calderona de un grupo de viviendas adosadas (Polígono R-3 de Santo Espíritu). Fotografía E. Burriel, junio de 2017. 
Hay otros costes colectivos importantes que no son económicos, como la pérdida casi total de credibilidad de la autoridad urbanística por su inacción durante años frente a las ilegalidades. Esto puede explicar la tolerancia posterior en Gilet con la excesiva edificabilidad de algunos desarrollos del suelo urbanizable -incluso con interpretaciones de las ordenanzas que vulneran la legalidad, como no computar la edificabilidad de garajes y terrazas- (Figura 13) o con diseños constructivos que producen un fuerte impacto paisajístico (Figura 14).

Estos costes colectivos se dan en todos los territorios en los que se desarrollaron las segundas residencias ilegales y se han convertido casi siempre en un lastre económico y político para la comunidad, sobre todo la local.

\section{El CAMBIO DEL MODELO RESIDENCIAL Y SUS CONSECUENCIAS}

Gilet -que se mantuvo en torno a los 1.000 habitantes desde principios del siglo XX hasta 1981- ha conocido un notable crecimiento demográfico en los últimas tres décadas: iniciado en los años 80, se disparó entre 2003 y 2009 coincidiendo con el boom inmobiliario con una tasa anual acumulada del $8.8 \%$ que duplicó la población en sólo 8 años; tras el estallido de la burbuja el incremento ha sido ya muy escaso. En 2019 tiene 3.365 habitantes, más del triple que en 1981. (Tabla 2)

Tabla 2. Evolución de la población de Gilet entre 1900 y 2019.

Fuente: Censos de Población y Padrón Continuo. Elaboración propia.

\begin{tabular}{|c|c|c|c|c|}
\hline \multirow{2}{*}{ Año } & \multirow{2}{*}{ Habitantes } & \multirow{2}{*}{ Período } & \multicolumn{2}{|c|}{ Incremento } \\
\cline { 4 - 5 } & & & Absoluto & Tasa anual \\
\hline 1900 & 852 & & & \\
\hline 1950 & 823 & $1901-1950$ & -29 & $-0,07$ \\
\hline 1960 & 1022 & $1951-1960$ & 199 & 2,19 \\
\hline 1981 & 993 & $1961-1981$ & -29 & $-0,26$ \\
\hline 1991 & 1184 & $1982-1991$ & 191 & 1,77 \\
\hline 2001 & 1550 & $1992-2001$ & 366 & 2,73 \\
\hline 2011 & 3248 & $2002-2011$ & 1698 & 7,68 \\
\hline 2019 & 3365 & $2012-2019$ & 117 & 0,34 \\
\hline
\end{tabular}


Este gran aumento demográfico se ha debido a la llegada de nuevos residentes, en su mayoría procedentes de Valencia y su área metropolitana, y ha originado una importante modificación de la composición de la población y de su distribución territorial que ha afectado también a los núcleos de origen ilegal.

Gilet -a $28 \mathrm{~km}$. de Valencia con acceso por vías de alta capacidad, y conocido y apreciado por los vecinos de la capital como área de residencia vacacional y de ocio festivo (Burriel, 2018, 28 y 47) - ha entrado a participar en el proceso de desconcentración urbana y redistribución espacial de la población acaecido en el entorno de todas las grandes áreas urbanas españolas en las décadas del cambio de siglo (Monclús, 1998; Nel·lo, 2004).

A la vez ha tenido lugar un drástico cambio en la ubicación de sus vecinos: de su total concentración en 1981 en el casco urbano - "el pueblo"- a su actual dispersión por todo el municipio. Los 993 habitantes de 1981 vivían todos en el casco salvo los pocos frailes del monasterio; las viviendas de Santo Espíritu y La Paz y de los núcleos ilegales sólo se utilizaban en las vacaciones de Pascua y de verano, en que el número de residentes en el municipio más que se duplicaba. Pero 2/3 de los 2.184 nuevos vecinos llegados desde 1991 han fijado su residencia en las urbanizaciones, tanto en las legales como en las de origen ilegal. En 2019 en las casas construidas en su día para vivienda secundaria hay empadronados 1.432 vecinos, un 43\% del total y más que habitantes tenía el municipio en 1991 (Tabla 3).

Tabla 3. Evolución de la distribución territorial de la población de Gilet entre 1991 y 2019. Fuente: INE. Nomenclator de 1991, 2000 y 2019. Elaboración propia.

\begin{tabular}{|l|c|c|c|c|c|c|}
\hline \multirow{2}{*}{ Núcleo } & \multicolumn{2}{|c|}{1991} & \multicolumn{2}{c|}{2000} & \multicolumn{2}{c|}{2019} \\
\cline { 2 - 7 } & Habitantes & $\%$ del total & Habitantes & $\%$ del total & Habitantes & \% del total \\
\hline Casco urbano & 1112 & 93,9 & 1167 & 79,0 & 1933 & 57,4 \\
\hline Urbanizaciones & & & & & & \\
\hline La Paz & 29 & 2,4 & 130 & 8,8 & 410 & 12,2 \\
\hline Santo Espíritu & 16 & 1,4 & 62 & 4,2 & 552 & 16,4 \\
\hline Núcleos de origen ilegal & 27 & 2,3 & 118 & 8,0 & 470 & 14,0 \\
\hline Total urbanizaciones & 72 & 6,1 & 310 & 21,0 & 1432 & 42,6 \\
\hline Total municipio & 1184 & 100 & 1477 & 100 & 3365 & 100 \\
\hline
\end{tabular}


Este cambio de modelo residencial, de municipio rural con urbanizaciones de residencia secundaria a zona de residencia permanente para personas que vivían en la ciudad de Valencia o su entorno más cercano, ha convertido a Gilet en un municipio dual en la composición y distribución de su población: por un lado, los autóctonos, residentes en el casco urbano, de raíces rurales y con fuerte arraigo familiar y territorial, que han pasado a ser minoría, menos de un tercio del total; y, por otro lado, los recién llegados, de origen urbano, residentes la mayoría en las urbanizaciones aunque una parte también en construcciones nuevas de adosados en la periferia del pueblo ${ }^{16}$.

Algunos de los nuevos vecinos eran propietarios de una vivienda de vacaciones que han convertido ahora en su residencia habitual; pero no pocos de ellos son nuevos en la zona, compradores de casas antiguas o de parcelas vacías en las que construyen una nueva. Hay jubilados, pero la mayoría están en activo y se desplazan cada día a su trabajo en Valencia o en otro municipio metropolitano.

La mayor parte han acudido en busca de las supuestas ventajas de residir en un entorno muy diferente al urbano del que proceden. Pero otros lo han hecho forzados por la crisis económica que les ha llevado a vender su casa de la ciudad o a cederla a algún hijo/a, o bien es a éste/a al que dejan la antigua vivienda secundaria. El papel de la crisis en el cambio de residencia se refuerza al constatar un mayor incremento de la población en las urbanizaciones de origen ilegal que en las legales de La Paz y Santo Espíritu con propietarios de superior nivel de renta; e incluso aquéllas son las únicas que aumentan tras el estallido de la burbuja inmobiliaria ${ }^{17}$.

En 2019 un 39\% de las viviendas de los núcleos de origen ilegal se utilizan como residencia permanente y en ellas están empadronados 470 vecinos, un 14\% de la población municipal. Casi 2/3 están en Balcó de la Penya y en los adosados de Camí del Convent-3, pero existen en todos los grupos incluso en los más aislados y de peores condiciones (Tabla 4). El uso habitual ha puesto más en evidencia las deficiencias de muchas de estas casas y las carencias de infraestructuras básicas, incrementando la presión a la administración para que se haga cargo de ellas.

16 Los grupos de adosados de alta densidad edificatoria se han localizado en tres zonas de la periferia del pueblo: al este, junto al barrio del Ventorrillo; en la parte alta; y al oeste, en la ladera baja de La Paz. Han contribuido a que el casco urbano también haya tenido un notable aumento demográfico, pasando de 1.167 habitantes en el año 2000 a 1.933 en 2019.

17 Entre 2012 y 2019 los núcleos ilegales crecieron en 51 vecinos mientras que Santo Espíritu y el casco urbano de Gilet perderon 31 y 67 respectivamente y La Paz sólo aumentó en 17. 
Tabla 4. Viviendas de origen ilegal que son residencia permanente en 2019. Fuente: Ayuntamiento de Gilet. Sede electrónica del Catastro: visualizador de inmuebles y visor cartográfico.

\begin{tabular}{|l|c|c|c|}
\hline Núcleos de origen ilegal & Total de viviendas & $\begin{array}{c}\text { Viviendas de residencia } \\
\text { permanente }\end{array}$ & $\begin{array}{c}\text { \% de viviendas de } \\
\text { residencia permanente }\end{array}$ \\
\hline Balcó de la Penya & 82 & 44 & 53,7 \\
\hline Calderona & 70 & 23 & 32,9 \\
\hline Camí del Convent & 115 & 60 & 52,2 \\
\hline Camí de la Costera & 14 & 3 & 21,4 \\
\hline Clot d'Oliver & 36 & 11 & 30,6 \\
\hline Pla de la Venta & 56 & 10 & 17,9 \\
\hline Vidriera & 41 & 11 & 26,8 \\
\hline Total & 414 & 162 & 39,1 \\
\hline
\end{tabular}

El cambio de modelo residencial de las parcelaciones desarrolladas al margen del planeamiento, de zona de vacaciones a cada vez más de primera residencia, y los problemas que ello acarrea, se está produciendo en todas las ubicadas en entornos urbanos, como se señala en Cataluña (Nel·lo, 2011a, 82), Aragón (Betrán, \& Franco, 1994, 107 y 255), Canarias (Parreño, 2006, 236) o Castilla La Mancha (Madrazo, \& Mato, 2002, 408).

Una buena parte de los parcelistas de origen ilegal pasan así a ser vecinos y con ello electores en el municipio y toman conciencia de la fuerza de sus votos que, aunque minoritarios, pueden resultar decisivos para el signo del gobierno local, lo que ha dado una dimensión política a la problemática de los núcleos ilegales. En Gilet ha sido tema clave de la política local en los últimos veinte años y ha afectado a la gobernanza municipal. En las elecciones locales de 2003 los votos de los empadronados en los núcleos que se negaban a cumplir con sus obligaciones urbanísticas fueron decisivos para que el PP, que les había prometido que no tendrían que pagarlas, accediera por primera vez a la alcaldía ${ }^{18}$. Como era de esperar no pudo cumplir su promesa porque rebasaba en mucho las posibilidades económicas del ayuntamiento y además suponía un agravio comparativo con los demás vecinos.

En las elecciones de 2007 se presentó una candidatura de residentes en las urbanizaciones, Agrupación de urbanizaciones de Gilet (AUG); obtuvo sólo un concejal pero fue el que resolvió el empate entre PP y PSOE a favor de éste último, por el incumplimiento anterior de los conservadores y porque en AUG eran mayoría los vecinos de las urbanizaciones legales de Santo Espíritu y La Paz. Esto permitió abordar las obras en los núcleos que habían aceptado desde el principio sus compromisos y conseguir el acuerdo de los propietarios de Calderona.

18 Parece que hubo un empadronamiento masivo de propietarios de las urbanizaciones para esas elecciones, pues en ese año electoral la población creció en 403 personas, más del doble que en cualquier otro de la década. 
Pero los parcelistas de Balcó de la Penya -y a su rebufo los de Camí del Convent-1 y Camí de la Costera- siguieron negándose a hacerse cargo de la urbanización; su actitud terminó rompiendo AUG y presentando aquéllos en 2011 su propia candidatura con la denominación de "Amb Trellat" (que, paradójicamente, quiere decir "con cordura"). Sus 153 votos les dieron un único concejal que volvió a ser decisivo para otorgar la alcaldía al PP, que de nuevo no pudo atender sus exigencias.

Tras las elecciones de 2015, que dieron mayoría a los partidos de izquierda y la alcaldía al PSOE, el ayuntamiento decidió pasar a la vía coercitiva e inició el proceso para la ejecución municipal de la urbanización en los núcleos que se negaban cargando a los propietarios las cuotas urbanísticas, lo que ha llevado a que éstos hayan firmado por fin en marzo de 2019 su compromiso de financiar las obras.

En la Comunidad Valenciana se constituyó en 2007 un "Partido Político Valenciano de las Urbanizaciones" (Pavalur), que pretendía ser un grupo de presión para aumentar la cantidad y calidad de los servicios de las áreas residenciales de origen ilegal (El Mundo, 2007). En Llíria, un municipio con 8.000 viviendas ilegales (Hermosilla, 1992, 98), surgió una "Federación de Urbanizaciones del Camp de Turia" (FUCTU) y una candidatura municipal, "Movimiento Vecinal" (MOVE) ante la exigencia municipal de dotarse de depuradoras o instalar alcantarillado y conectarlo a la red municipal (Levante, 2017, enero 15). En las recientes elecciones municipales de 2019 candidaturas de urbanizaciones han resultado claves para decidir el signo del gobierno en varios municipios (Chiva, Godelleta, la Pobla de Vallbona, Puçol, Bétera...)

Este impacto de los problemas de las viviendas secundarias ilegales en la política local tampoco es una singularidad de Gilet ni de la Comunidad Valenciana. En otros territorios han aparecido también candidaturas de "chaleteros" con la excusa de defenderse del supuesto maltrato de los gobiernos municipales y conseguir resolver sus deficiencias infraestructurales sin coste para ellos. Sus protestas aparecen con cierta periodicidad en la prensa, atribuyendo toda la responsabilidad de sus carencias a la administración, olvidando, o desconociendo por el paso de tanto tiempo, que esas actuaciones eran obligación suya. Sus concejales, muchas veces decisivos, han actuado en defensa casi exclusiva de sus intereses privados (Betrán, \& Franco, 1994, 79; Olmedo, 2016, 3; Jiménez Barrado, 2018, 158).

La persistencia de problemas de todo tipo en los núcleos de viviendas ilegales, agravados por el progresivo cambio a residencia habitual, ha acabado convirtiendo a una parte de la representación ciudadana en un grupo de presión política que va a utilizar su poder exclusivamente para intentar que la administración se haga cargo de solucionar sus déficits urbanísticos. Su dedicación a intereses muy sectoriales y por lo general no justificables han complicado la gobernabilidad en no pocos municipios. 


\section{Conclusiones}

1. Se ha podido comprobar la hipótesis de que las viviendas secundarias desarrolladas al margen de la legalidad han dejado una profunda huella negativa en el territorio, que además perdura mucho en el tiempo y en algunos aspectos resulta de muy difícil solución. Las principales consecuencias son desorden territorial, importantes impactos ambientales y paisajísticos, carencia o mala calidad de infraestructuras y dotaciones básicas, elevados costes económicos y sociales para la colectividad e incluso problemas para la gobernabilidad municipal.

2. Se ha demostrado también la hipótesis de que la causa básica de esta profunda huella en el territorio, de su perduración en el tiempo y de la dificultad de darle solución radica en el carácter sustancial de la ilegalidad de este producto urbanístico. De ella derivan los dos factores determinantes de su huella territorial: la localización inadecuada de estos núcleos residenciales y la negativa de los propietarios a cumplir con sus obligaciones urbanísticas. Convertir en legal un proceso que sólo fue posible por su ilegalidad resulta una contradicción difícil de superar.

3. A posteriori no es posible aprobar un planeamiento racional en un territorio parcelado y edificado de modo desordenado. No se ha recuperado casi nunca la legalidad mediante la eliminación de lo construido indebidamente. No han dado resultado ninguna de las alternativas planteadas para conseguir un espacio ordenado y con las infraestructuras y servicios exigibles en un área residencial: ni la modificación del plan para su clasificación como suelo urbano -que, al contrario, ha consolidado más su situación sin resolver los déficits- ni como suelo urbanizable que se ha revelado de imposible gestión; ni tampoco la opción más blanda de muchas normativas autonómicas de mantenerlos como "asentamientos de población en suelo no urbanizable" con la obligación de un mínimo de infraestructuras para reducir su afección territorial.

4. Resulta muy difícil conseguir que unos propietarios que lograron satisfacer su deseo de una vivienda secundaria precisamente por los costes mucho más bajos que permitía la ilegalidad acepten hacerse luego cargo de las infraestructuras y dotaciones que buscaron ahorrarse. El bajo nivel de renta de la mayoría no les permite hacer frente a los elevados costes de estas obras, todavía más caras a posteriori; más aún cuanto que ya han obtenido el beneficio buscado, el aprovechamiento urbanístico. Luego, su negativa se refuerza porque están convencidos de que no les va a pasar nada por su experiencia de la falta de presión efectiva de las administraciones y de que el paso del tiempo consolida su situación y su resistencia les acaba siendo beneficiosa.

5. El reciente proceso de descentralización urbana ha alcanzado también a zonas donde hace casi medio siglo se ubicaron las residencias secundarias ilegales, haciendo que muchas de ellas hayan pasado a ser residencia habitual. Esto ha puesto más en evidencia sus deficiencias urbanísticas y ha incrementado la presión a la administración para que 
se haga cargo de las carencias; algo que con frecuencia han acabado consiguiendo total o parcialmente, sobre todo cuando sus votos como nuevos vecinos se han convertido en claves para el gobierno municipal.

6. Resulta evidente la imposibilidad de dar una solución adecuada a los núcleos de viviendas ilegales una vez consolidados; sólo caben medidas mitigadoras, que además no resultan fáciles de implementar por la fuerte resistencia de los propietarios a financiarlas.

Por ello la única alternativa eficaz es atajar de plano el proceso en sus inicios. Su desarrollo no ha sido un problema de normativa, que nunca las ha permitido, sino de un apoyo social mayoritario a estas viviendas que, junto a la falta de conciencia de sus graves consecuencias, explica la actitud pasiva cuando no cómplice que con demasiada frecuencia adoptaron las administraciones competentes. Cuando el ayuntamiento de Gilet, consciente del problema territorial que suponían, decidió en 1983 controlarlas su construcción cesó rápidamente, como ocurrió en esos años en las principales áreas metropolitanas. En cambio, en esa década, a pesar de la aprobación de prolijas regulaciones autonómicas, empezaron a surgir nuevos conjuntos ilegales en otras regiones en las que un desarrollo económico y social más tardío mantenía su aceptación social.

La importancia e irreversibilidad de los impactos territoriales de estos núcleos ilegales no permite esperar a su progresivo rechazo por una sociedad más desarrollada y exige a las administraciones competentes extremar su control y una aplicación rigurosa de la disciplina urbanística para impedirlas desde el principio. Para evitar la posible renuencia a actuar de algunos municipios por su cercanía a los afectados la administración autonómica debe de tener competencias para actuar subsidiariamente con rapidez.

\section{Referencias}

Betrán Abadía, R. y Franco Hernández, Y. (1994): Parcelaciones ilegales de segunda residencia. El caso aragonés. Zaragoza: Diputación General de Aragón, Departamento de Ordenación del Territorio, Obras Públicas y Transportes.

Burriel, E.L. (2016): Empty urbanism: the bursting of the Spanish housing bubble. Urban Research $\mathbb{E}$ Practice, 9(2), 158-180. http://dx.doi.org/10.1080/17535069.2015.1110196

Comunidad de Madrid (1984): Urbanizaciones ilegales. Programa de Actuaciones y Catálogo, Madrid, Comunidad de Madrid, Consejería de Ordenación del Territorio, Medio Ambiente y Vivienda, Dirección General de Urbanismo, 2 vol.

Defensor del Pueblo Andaluz. (2000): Las urbanizaciones ilegales en Andalucía. Informe especial al Parlamento. Sevilla: Defensor del Pueblo Andaluz. Recuperado de Boletín Oficial del Parlamento de Andalucía (BOPA), 58 website: http://www.parlamentodeandalucia.es/webdinamica/portal-web-parlamento/pdf.do?tipodoc $=$ bopa\&id=4865 
Delgado Viñas, C. (2011): Efectos territoriales, socioeconómicos y legislativos del urbanismo expansivo de Cantabria. En Gozálvez, V. y Marco, J. A. (ed.): Urbanismo expansivo: de la utopía a la realidad. Comunicaciones. XXII Congreso de Geógrafos Españoles, Universidad de Alicante, 2011 (Asociación de Geógrafos Españoles (AGE), Universidad de Alicante, Colegio de Geógrafos de España, pp. 203-215). Recuperado de http://hdl.handle.net/10045/48435

Diputación Provincial de Valencia (1983): Urbanismo y vivienda rural. Valencia: la vivienda ilegal de segunda residencia. Valencia: Diputación Provincial de Valencia.

Dirección General del Catastro. Sede electrónica del Catastro. Gilet (s. f.): Recuperado 23 de abril de 2019, de Buscador de inmuebles y visor cartográfico. website: https://www1.sedecatastro.gob.es/ Cartografia/mapa.aspx?del $=46 \&$ mun $=136$

El Mundo (2007, febrero 13): Seis áreas residenciales de Valencia y Alicante plantean unirse al partido de las urbanizaciones. El Mundo.

Fajardo de la Fuente, A. (2003): La pérdida de los valores paisajísticos y ambientales en el término municipal de Osuna por la proliferación de urbanizaciones ilegales. Cuadernos de los Amigos de los Museos de Osuna, 5, 17-23.

García Bellido, J. (1986): La cuestión rural. lndagaciones sobre la producción del espacio rústico. Ciudad y Territorio, 69, 9-51.

García Lliberós, M. (1983): Haciendas locales y urbanizaciones ilegales. En Diputación Provincial de Valencia (ed.): Urbanismo y Medio Rural. Valencia: la vivienda ilegal de segunda residencia (pp. 4956). Valencia: Diputación Provincial de Valencia.

Gobierno de Aragón, Dirección General de Ordenación del Territorio y Urbanismo (ed.) (1997): La disciplina urbanística: el suelo no urbanizable, las parcelas ilegales y el nuevo código penal: actas I y II jornadas. Zaragoza: Diputación General de Aragón, Departamento de Ordenación Territorial, Obras Públicas y Transportes

Henry, G. (2007): Los costes económicos y sociales de la ciudad de baja densidad. En Indovina, F. (coord.): La ciudad de baja densidad. Lógicas, gestión y contención (pp. 203-241). Barcelona: Diputación de Barcelona.

Herce Vallejo, M. (1997): La legislación urbanística vigente y las posibilidades de tratamiento de las parcelaciones ilegales desde el planeamiento y la gestión. En La disciplina urbanística: el suelo no urbanizable, las parcelas ilegales y el nuevo código penal. Actas I y II Jornadas. (pp. 117-124). Zaragoza: Diputación General de Aragón, Departamento de Ordenación Territorial, Obras Públicas y Transportes.

Hermosilla, J. (1992): La residencia secundaria en la periferia occidental del área metropolitana de Valencia. Cuadernos de Geografía, 51, 95-109.

Jiménez Barrado, V. y Campesino Fernández, A.J. (2017): Deslocalización de lo urbano e impacto en el mundo rural: rururbanización en «pueblos dormitorio» de Cáceres capital. Cuadernos Geográficos, 57(3), 243-266. http://dx.doi.org/10.30827/cuageo.v57i3.6239 
Jiménez Barrado, V., Delgado Viñas, C., y Campesino Fernández, A.J. (2017): Desregulación urbanística del suelo rústico en España. Cantabria y Extremadura como casos de estudio. Revista de Geografía Norte Grande, 67, 73-92.

Jiménez Barrado, V. (2018): Urbanizaciones ilegales en Extremadura: La proliferación de viviendas en el suelo no urbanizable durante el período democrático (Universidad de Extremadura). Recuperado de https://www.educacion.gob.es/teseo/imprimirFicheroTesis.do?idFichero=a1VWdZ8yFuI\%3D

Levante-El Mercantil Valenciano (2012, octubre 18): Gilet puede ser multado con un millón por falta de alcantarillado. Levante-El Mercantil Valenciano. Recuperado a partir de https://www.levante-emv.com/comarcas/2012/10/18/gilet-multada-millon-falta-alcantarillado/944850.html

Levante-El Mercantil Valenciano (2017, enero 15): El Supremo obliga a 7.000 chalets de Lliria a instalar depuradoras para sus vertidos. Levante-El Mercantil Valenciano. Recuperado a partir de https:// www.levante-emv.com/comarcas/2017/01/15/supremo-obliga-7000-chalets-lliria/1515513.html

Levante-El Mercantil Valenciano (2017, noviembre 22): Tres mil chalets de Calicanto carecen de alcantarillado y vierten en fosas sépticas. Levante-El Mercantil Valenciano.

Levante-El Mercantil Valenciano (2017, noviembre 23): Vecinos de Calicanto: Aquí el agua siempre ha sido mala, pero nunca tan peligrosa. Levante-El Mercantil Valenciano. Recuperado a partir de https://vecinoscalicanto.org/wp-content/uploads/2017/11/Vecinos-de-Calicanto___Aqui\%CC\%81el-agua-siempre-ha-sido-mala-pero-nunca-tan-peligrosa_-Levante-EMV.pdf

Madrazo García de Lomana, G., y Mato Miguel, J.F. (2002): Urbanización e intensificación ganadera en la vega de Talavera: problemas sociales y ambientales. En Asociación de Geógrafos Españoles. Grupo de Geografía Rural (Ed.), Los espacios rurales entre el hoy y el mañana. Actas del XI Coloquio de Geografía Rural, Santander, 2002 (pp. 401-411). Santander: Universidad de Cantabria. Servicio de Publicaciones.

Martín Fernández, C.S. (2011): El proceso reciente de regulación de la vivienda ilegal en Canarias (1996-2009). Boletín de la Asociación de Geógrafos Españoles, 57, 101-122.

Monclús, F.J. (1998): Suburbanización y nuevas periferias. Perspectivas geográfico-urbanísticas. En Monclús, F.J. (ed.): Urbanismo, ciudad, historia (I). La ciudad dispersa. Suburbanización y nuevas periferias (pp. 5-15). Barcelona: Centre de Cultura Contemporània de Barcelona.

Mur, S. y Clusa, J. (2011): El balanç fiscal municipal insostenible de la ciutat de baixa densitat. En Muñoz, F. (coord.): Estratègies vers la ciutat de baixa densitat: de la contenció a la gestió (pp. 333-356). Barcelona: Diputació de Barcelona.

Nel·lo, O. (2004): Las grandes ciudades española en el umbral del siglo XXI. Papers. Regió Metropolitana de Barcelona, 42, 9-62.

$\mathrm{Nel} \cdot \mathrm{lo}, \mathrm{O}$. (2011a): Estrategias para la contención y gestión de las urbanizaciones de baja densidad en Cataluña. Ciudad y Territorio. Estudios Territoriales, 167, 81-98.

Nel·lo, O. (2011b): Les urbanitzacions amb dèficits urbanístics: de la utopía a la gestió. En Muñoz, F. (coord.): Estratègies vers la ciutat de baixa densitat: de la contenció a la gestió (pp. 221-252). Barcelona: Diputació de Barcelona. 
Olmedo Pérez, S. (2016): Reflexiones sobre las edificaciones clandestinas en suelo no urbanizable en Andalucía y los intentos de la Comunidad Autónoma de Andalucía para su reconducción. Política urbanística. Revista mensual de urbanismo, 139, 1-29.

Parreño Castellano, J. F. (2006): La vivienda en el medio rural de Canarias (España): diagnosis y criterios de ordenación. Vegueta. Anuario de la Facultad de Geografía e Historia, 9, 219-242.

Pérez Puchal, P. (1968): El paisaje agrario del Bajo Palancia. Valencia: Institución Alfonso el Magnánimo, Diputación Provincial de Valencia.

Sindic de Greuges (2013): Informe sobre les urbanizatcions amb dèficits. Recuperado de http://www.sindic.cat/site/unitFiles/3451/Informe\%20urbanitzacions-CAT.pdf

Cómo citar este artículo:

Burriel, E. L. (2019). La larga huella en el territorio de las viviendas secundarias ilegales.

El ejemplo de Gilet (Valencia). Cuadernos de Geografía, 102, 107-140.

https://doi.org/10.7203/CGUV.102.15004

\section{(c) $(1) \Theta \Theta$}

Este obra está bajo una licencia de Creative Commons Reconocimiento-NoComercial-SinObraDerivada 4.0 Internacional. 
